\title{
Die Kinderlähmung im Großherzogtum Hessen während der Jahre 1909 bis 1914. Von
}

Med.-Rat Dr. Langermann, Krelsarzt zo Bebsheim, zurzelt in Felde.

\section{Geschichtliche Übersicht.}

Die seit vielen Jahren unter dem Namen Heine-Medinsche Krankheit, spinale (epid.) Kinderlähmung, Poliomyelitis anterior acuta usw. bekannte Erkrankung wurde zuerst im Jahre 1840 von dem Stuttgarter Arate Jakob v. Heine genaner beschrieben, der damals rein deduktir den Sitz der Erkrankung in das Rückenmark verlegte und so den Namen „spinale Kinderlähmung" im Gegensatz zu den zerebralen Eirkrankungen prägte. In pathologisch-anatomischer Hinsicht konnten schon im Jahre 1863-65 Cornil, Prévost und Vulpian und später Charcot in chronischen Fällen eine Atrophie der Vorderhörner mit Schwund der Ganglienzellen und RiBler im Jahre 1888 Entzündungserscheinungen am GefäBapparat und ebenfalls Degeneration der Ganglienzellen auch im akuten Stadium feststellen (Poliomyelitis ant. acuta). AuBer verschiedenen anderen Forschern (Leegard, Mönckeberg usw.) veröffentlichte später im Jahre 1905 Ivar Wickmann, Privatdozent an der Universität Stockholm, anläBlich der dortigen Epidemie eine Reihe von Fällen im akuten Stadium in pathologisch-histologischer Hinsicht. In klinischer Beziehung konnte Prof. Medin gelegentlich der Stockholmer Epidemie im Jahre 1887 und 1895 nachweisen, daB neben der rein spinalen Form auch noch Erkrankungen bulbären, polyneuritischen, ataktischen und enzephalitischen Charakters unterschieden werden müBten, eine Forderung, die vorher schon Strümpell vertreten hatte. Eine gewisse Abrundung unserer 
Kenntnisse über diese Krankheit brachten dann zugleich die klinischen Studien Wickmanns, der das Krankheitsbild noch erweiterte. Diese Forschungen wurden nun im Laufe der Jahre anläBlich der großen Epidemien in Schweden 1899/1906, in Norwegen in den Jahren 1903-05, in England 1904, in Rußland 1905, 1909/10, in den Vereinigten Staaten von Nordamerika 1907-10, in Osterreich und Frankreich 1908/09 und zuletzt in Deutschland von 1908-14 vollauf bestätigt. Öber die Natur der Krankheit hatte man in der allerersten Zeit ungenaue Vorstellungen, bis Strümpell 1884 und Pierre Marie sie nach ihrem ganzen Verhalten als Infektion hinstellten. Diese Ansicht wurde gestützt durch die weitere Beobachtung, daß die Krankheit gruppenweise und endemisch auftreten konnte (1881, 87, 95, 97, 98 Kiel-Frankfurt). Die Verbreitungsart der späteren Epidemien aufzuklären gelang erst Wickmann, der damals durch Feststellung sogenannter abortiver Formen nachweisen konnte, daB sich die Erkrankung ähnlich wie bei anderen Infektionskrankheiten durch direkteu oder indirekten Kontakt von Person zu Person übertragen lieB, eine Tatsache, die von allen neueren Forschern in den letzten Epidemien bestätigt wurde. Natürlich hat es auch nicht seit Beginn der 90er Jahre an Versuchen gefehlt, den unbekannten Erreger dieser Krankheit mikroskopisch und kulturell nachzuweisen, speziell im erkrankten Rückenmark und in der Zerebrospinalflüssigkeit. Aber alle gefundenen Bakterienarten konnten auf die Dauer nicht als der Erreger der Kinderlähmung angesprochen werden. Als Fazit der bis zum Jahre 1910 sich hinziehenden Untersuchungen ergab sich, daB der Erreger eine filtrierbare Virusart darstellt, sehr klein und glyzerinbeständig ist, sowie färberisch und kulturell schwer nachweisbar sein dürfte.

\section{Neuere Forschungsergebnisse. Symptomatologie.}

Am besten beobachtet und beschrieben ist natürlich das klinische Bild der Kinderlähmung. Die meisten Forscher teilen sie in zwei Zwischenstufen ein: 1. das Stadium der Allgemeinerscheinungen mit Symptomen der allgemeinen. Infektion (Schwäche, Unlust, Kopfweh, Schmerzen im Nacken, in dem Rücken und in den Beinen, auffallende Schmerzhaftigkeit bei Druck auf die Wirbelsäule, Fieber, Magendarmkatarrh mit Durchfall und Erbrechen, .wechselnd mit Verstopfung, manchmal auch leichte Angina, Katarrhe, Schnupfen, Hautausschläge, Konvulsionen mit ofters getrübtem Sensorium und ferner, als Kardinalsymptome, Utberempfindlichkeit bei Berührung und passiven Bewegungen, sowie starker Schweißausbruch) und dann 2. das Stadium der Lähmuingen. Bezüglich dieser vielgestaltigen Lähmungen unterscheidet man am besten folgende 
drei Formen: a) Spinale Form. Die Lähmungen können dabei fast alle Iuskelgruppen befallen. Sie treten meist zuerst als Paresen auf und erstrecken sich auf mehrere Muskeln; später lokalisieren sie sich und führen zur schlaffen, atonischen Lähmung mit Atrophie und Verlust der elektrischen Erregbarkeit (Entartungsreaktion). Nach den Statistiken werden am meisten befallen: ein Bein, dann zwei Beine, dann Arm und Bein, des weiteren der Rumpf und zuletzt beide Arme. Von den Muskeln der unteren Extremitäten werden am häufigsten ergriffen die Musculi peronei und der Quadriceps, von denen der oberen die Schultermuskulatur. Ofter wurde auch eine Lähmung der Interkostalmuskeln, selten eine solche des Zwerchfelles beobachtet. Lähmung der Rumpfmuskulatur findet sich dagegen ziemlich häufig kombiniert, besonders beim Beginn, so daB sich die Kinder nicht aufsetzen können. Die Sehnenreflexe sind teils herabgesetzt, teils erloschen, die anderen Reflexe meist erhalten. Manchmal wurde auch eine gesteigerte Reflexerregbarkeit beobachtet. Lähmungen der Blase und des Mastdarmes sind selten. Grobe Sensibilitätsstörungen fehlen; gelegentlich kommen Anästhesien und Hyperästhesien vor. An das akute Lähmungsstadium schlieBt sich nun, falls nicht der Tod plötzlich eintritt, das der Ausheilung und an dieses nach $1 \frac{1}{2}$ bis 2 Jahren das chronische atrophische Stadium mit definitiven Lähmungen und Deformitäten (SpitzfuB-, KJumpfuBstellung, Schlottergelenke, Vorbiegung der Wirbelsāule usw.) neben trophischen Störungen der Haut und der Knochen an. Ofter entwickelt sich die Krankheit in Schüben; es tritt dann nach Wochen und Monaten ein Rezidiv ein. b) Zerebrale Form: Sehr oft werden auch die Hirnnerven allein oder mitergriffen, so am häufigsten der Fazialis einseitig, oft kombiniert mit Lähmung des Hypoglossus, selten des Abducens, Oculomotorius und Opticus und am wenigsten die andẹren Gehirnnerven. Manchmal aber auch tritt die Lähmung ron den Beinen und Armen aus rasch auf das bulbäre Zentrum und führt in einigen Tagen zum Tode unter Erscheinungen von Atemlähmungen (aufsteigende Landrysche [Bulbär-] Paralyse). Die absteigende Form ist dagegen sehr selten. Ein Teil dẹ Fälle verläuft auch unter deutlich ataktischen und spastischen Erscheinungen mit Steigerung der Reflexe (zerebellare, Friedreichsche Ataxie). Zu dieser zerebralen Form der Kinderlähmung rechnet man am besten auch die polyneuritische mit neuritisähnlichen Symptomen (starke. Schmerzen und Druckempfindlichkeit der Nerrenstämme), die sicherlich durch zentrale Veränderungen hervorgerufen wird. Hierher gehört wobl auch die sogenannte meningitische Form der Kinderlähmung, wobei die: meningitischen Reizsymptome (Kopfweh, Erbrechen, Nacken- und Rücken-. steifigkeit, tonische und klonische Zuckungen, Aufhebung des Sensoriums usw.) so in den Vordergrund treten, daB man das Bild einer: 
Basilarmeningitis vor sich zu haben glaubt. Dann aber lassen die Reizerscheinungen nach; es tritt entweder völlige Genesung oder die charakteristische Lähmung ein. c) Abortive Formen. Es ist das Verdienst Wickmanns, darauf hingewiesen zu haben, daB in einer groBen Anzahl von Fällen, die sicherlich mit Kinderlähmung zusammenhängen, es zwar nicht zur typischen Lähmung kommt, sondern es erfolgt nach den fieberhaften Allgemeinstörungen, wobei bald die Magendarmerscheinungen, die meningitischen, respiratorischen und influenzaähnlichen Symptome mehr in den Vordergrund treten, Ausheilung. Gelegentlich resultieren aber auch nur geringgradige Lähmungen (Paresen), die in wenigen Tagen bei erhaltenen Reffexen verschwinden. Die Abgrenzung dieser abortiven Fälle von den anderen ist somit nicht ganz scharf; Ubergänge kommen immer vor. Speziell unsere deutschen Forscher, wie Prof. Müller-Marburg und Grober-Essen, haben verhältnismäBig viele solcher abortiver Erkrankungen beobachtet und beschrieben.

\section{Inkubation, Prognose, Diagnose.}

Das Inkubationsstadium beim Menschen soll nach den Untersuchungen während der letzten Epidemien 3-5-7 Tage betragen, in einigen Fällen auch bis zu 10 Tagen. Bei der künstlichen Übertragung des Krankheitsgiftes auf Affen betrug die Inkubationszeit nach Prof. RömerMarburg durchschnittlich 9 Tage.

Was die Prognose anbelangt, so galt seither der Satz, daB dieselbe quoad vitam gut, quoad sanationem infaust sei. Nach den Ergebnissen der letzten Epidemien ist dies aber nicht richtig. Die Mortalitätsziffer schwankt allerdings in den einzelnen Epidemien sehr stark, beträgt aber immerhin in den schwedischen, norwegischen, österreichischen, amerikanischen, französischen und deutschen Epidemien im Durchschnitt 13 bis 14 Prozent. Auch ist die Sterblichkeit bei Erwachsenen über 10 Jahren nach Wickmann doppelt so groB, wie bei Kindern unter 10 Jahren. Hinsichtlich der Heilbarkeit der Lähmungen fand derselbe Autor einen vollständigen Ausgleich in etwa 20 Prozent. Nach Prof. Ed. Mũller sind etwa nur in einem Drittel der Fälle schwere und ausgebreitete Lähmungen zurückgeblieben.

Die Diagnose auf Kinderlähmung kann im allgemeinen gestellt werden, wenn nach einem akuten, kurzen Vorstadium mit leichtem Fieber sich Lähmungen einstellen, die schlaffer Art sind und besonders die Beine, die Rumpfmuskeln, die Arme oder die Kopfnerven befallen. Aber auch ohne ausgeprägte Lähmungen ist im Vorstadium schon die Diagnose möglich, wenn man, zumal gelegentlich einer Epidemie, die charakteristi- 
schen Symptome der Tberempfindlichkeit, der Steifigkeit des Nackens und des vermehrten SchweiBausbruches beachtet. Differentialdiagnostisch kämen nur in Betracht: Rheumatismus, Influenza, fieberhufter Brust- und Darmkatarrh, Halsentzündung, Zerebrospinalmeningitis, Meningitis (tuberculosa), infektiöse und periphere Neuritis, periphere Lähmungen, Myelitis, Hysterie, Coxitis, andere Infektionskrankheiten usw.

Anhangsweise ist noch die sogenannte sporadische Form der Kinderlähmung zu erwähnen, die in den früheren Jahren vor dem Auftreten von Gruppenerkrankungen und Epidemien die einzig beobachtete Art war. Nach den neueren Forschungen ist dieselbe nun mit der epidemischen wesensgleich, da ja während der Epidemien gleichartig verlaufende Erkrankungen zur Untersuchung kommen, beide dieselben Kardinalsymptome aufweisen, und zudem die Identität dieser sporadischen Erkrankungen mit den epidemischen serologisch und auch durch Tierversuch sichergestellt ist.

\section{Pathologische Anatomie.}

Für die Krankheit allein charakteristisch sind die Veränderungen am Zentralnervensystem. In stärker ausgeprägten Fällen ist das Rückenmark serös durehtränkt, die Schnittfläche quillt etwas stärker vor, die grave Substanz und besonders die.der Vorderhörner ist hyperämisch und oft mit Blutungen durchsetzt. Auch die weiße Substanz zeigt oft serōse Durchtränkung. Auch am Gehirn zeigen sich meist Hyperämie und Odem und rosarote Verfärbung. Die GefäBe der harten und weichen Häute sind gewöhnlich prall mit Blut gefüllt. Mikroskopisch handelt es sich um eine infiltrative Form der disseminierten Myeloencephalitis mit besonderer Beteiligung der grauen Substanz, und hier wieder meist im Bereiche der Vorderhörner des Rückenmarkes, und um Affektion der Häute (Leptomeningitis, Harbita und Schüle). Diese Veränderungen können auch auf die graue Substanz des Gehirns und verlängerten Markes, ja selbst auf die weiße Substanz übergehen. Es handelt sich danach, besonders in abgelaufenen Fällen, um eine disseminierte Entzündung des Rückenmarkes, der Medulla oblongata, des Pons, sowie groBer Teile des Gehirns. Eine intensive kleinzellige Infiltration schiebt sich besonders in die Lympfgefāße entlang der Gefäße in die Gehirn- und Rückenmarkssubstanz vor und bewirkt so einen Schwund der Ganglienzellen. Das Gift der Kinderlähmung scheint danach eine besondere Affinität zum Lymphapparat zu haben und erreicht anscheinend nach Art des Eindringens auf dem Wege der Lymphbahnen die peripheren Nerven, rein lymphogen den GefäBen entlang das Zentralnervensystem und hier wieder vorwiegend die gefäßreichen Vorderhörner. 


\section{Atiologie.}

Die Kinderlāhmung, die in frūheren Jahren nur sporadisch auftrat, hat jetzt ihren Charakter geändert; sie dehnt sich mehr aus, tritt epidemisch auf und zeigt sich als Volksseuche. Die Virulenz der Keime hat zugenommen; die Mortalität ist gestiegen. Direkt ausschlaggebend für die Annahme der Kinderlähmung als kontagiöse Krankheit ist aber der Umstand anzuführen, daB es zuerst Landsteiner zusammen mit Popper und später Römer, Levaditi, Flexner und Lewis neben anderen gelang, das Leiden auf Affen zu übertragen, und von Generation auf Generation in diesem Tierkörper zu züchten. Das bei diesen Tieren, die besonders für das Gift empfänglich sind, erzeugte Krankheitsbild gleicht nun klinisch und auch pathologisch-histologisch völlig demjenigen beim Menschen. Bei den ersten Versuchen Landsteiners wurde die Rückenmarksemulsion in die Bauchböhle verimpft, später wurde ansschlieBlich als sicherster Infektionsmodus die intrazerebrale Virusinjektion gewählt. Durch diese Verimpfbarkeit von Affe zu Affe bis zur 20. Generation in immer weiter absteigender Virusmenge ist zugleich der Beweis erbracht, daß die Verānderungen im Gehirn und Rückenmark der erkrankten Tiere durch ein belebtes Virus, also durch eine sich fortpflanzende Bakterienart, erzeugt wurden. Bezüglich der Immunitātsvorgänge bei der akaten Poliomyelitis lieB sich nun experimentell feststellen, daB Affen, die eine Infektion mit den Gift auch ohne nachweisbaren klinischen Befund durchgemacht hatten, sich meist immun gegen eine erneute Übertragung zeigten (Flexner und Lewis, Römer und Joseph, Landsteiner und Levaditi). Die Antikörper im Blute der Affen neutralisierten in vitro die Wirkung des Virus, Auch im Serum von Personen, die eine Poliomyelitis überstanden hatten, lieBen sich die Antikörper auf diese Art noch nach Monaten oder Jahren nachweisen. Netter und Levaditi fanden, daB dies auch für die abortiven Fälle zutraf, also für diejenigen Erkrankungen, die nur unter dem Bilde der Allgemeininfektion ohne Lähmungen verliefen. Andere fanden das Serum auch bei gesunden Menschen wirksam, die nachweislich mit Poliomyelitiskranken in Berührung gekommen waren, eine Tatsache, die vielleicht später einmal in serologisch-diagnostischer Beziehung Verwendung finden kann. Kling und Pettersson konnten die Existenzmöglichkeit von gesunden Keimträgern dadurch beweisen, daB sie das eingedickte Spülwasser aus Mund und Rachen der gesund gebliebenen Angehörigen von erkrankten Personen Affen injizierten, worauf unter 8 Fällen ein Affe richtige Poliomyelitis sich erwarb. Versuche, eine Komplementbindungsreaktion ähnlich der Wassermannschen zustande zu bringen, hatten bis jetzt im allgemeinen ein negatives Resultat. Im 
Blute, der Zerebrospinalflüssigkeit und in anderen Organen lieB sich das Gift nur ausnahmsweise feststellen; einmal wurde es in den Mesenterialdrūsen eines verstorbenen Kindes gefunden. In den Tonsillen, der Rachenschleimhaut, sowie in den Schleimhäuten der Nase und des Mundes fand es sich dagegen oft nach den Untersuchungen des Pasteurschen Instituts, die auch von anderen Forschern bestätigt wurden, aber im allgemeinen selten in den Sekreten aus Nase, Mund, Rachen, Luftröhre und Darm ron Erkrankten. Ebenso gelang der Nachweis des Virus in der Nasenpharynxschleimhaut von Affen, die künstlich intrazerebral infiziert waren. Durch gelungene Injektion des Giftes unter die Haut, in die Nähe der großen Nerven und in die Schleimhaut der Nase ron solchen Tieren lieb sich weiter eruieren, daB dasselbe auf dem Wege der Lymphbahnen den Nerven entlang zum Zentralnervensystem und speziell zum Rückenmark strömt. Auch gelang in den einzelnen Fällen die Infektion durch Injektion in die tieferen Respirationsorgane und den Magendarmkanal unter besonderen Bedingungen (Hungerzustand, Neutralisation des Magensaftes, Aufheben der Peristaltik durch Opium usw.). Auch festes Einreiben des Virus in die Nasenschleimhaut (wohl mit kleinen Lãsionen derselben) hatte Erfolg. Dagegen gelang die Ubertragung des Giftes auf Affen bei den sogenannten sporadischen Fällen sehr schlecht. Aber auch hier lonnte durch Tierpassagen die Virulenz gehoben werden, wie dies, auch bei anderen weniger virulenten Stämmen der Fall war. Das Gift fand sich nun meist tierexperimentell nachweisbar nicht allein in den Sekreten der Erkrankten, sondern auch in denjenigen von Gesunden der näheren Umgebung, wie dies ron Kling, Wernstedt und Pettersson, sowie von Flexner und Thomsen festgestellt wurde. Wenn nun auch der kranke Mensch entweder direkt oder indirekt die fast ausschlieBliche Ansteckungsquelle bilden wird, so kann das Gift sich auch im Schmutz und Staub der Straße finden, ja an leblosen Gegenständen, so an Taschentüchern von Erkrankten haften, wie dies ron Neustädter und Thro konnte nachgewiesen werden. Auch im Staub der Krankenzimmer fand es sich; desgleichen hielt es sich an Nahrungsmitteln (Milch, Obst, Wasser usw.) längere Zeit lebendig. Auch durch Vermischen mit Pockenfaccine lieB sich das Virus wie bei der Impfung auf Tiere übertragen (Thomsen). Gelegentlich der Epidemien in Schweden und Massachusetts wurde zum ersten Male auf den Zusammenhang von Kinderlähmung mit ähnlichen Erkrankungen der Haustiere (Hunde, Hühner, Enten usw.) aufmerksam gemacht. Bei uns in Deutschland lenkte zuerst KrauseBonn gelegentlich der rheinisch-westfälischen Epidemie und später Müller-Marburg und Bruno-Heidelberg erneut die Aufmerksamkeit auf diese merkwürdige Tatsache. Bruno berichtet über zwei im August 1913 
beobachtete Erkrankungen in einer Familie eines Vorortes von Heidelberg, wo der Vater aus der Nähe von Paderborn Enten erhalten hatte, die Anfang Juli an Lāhmungen erkrankten. Ähnliche Vorkommnisse sollen sich in der Familie eines Viehwärters in Form von Lähmung eines Rindes und in dem Orte Landhausen bei Heidelberg abgespielt haben. Nach den neueren Untersuchungen von Lust und Rosenberg konnten diese das Vorkommen gelähmter Tiere in Poliomyelitisgegenden und -zeiten bestätigen, es konnten auch bei verendeten Tieren eine, ausgebreitete, disseminierte Encephalitis und Meningitis nachgewiesen werden. Es miBlang aber der Versuch, die tbertragung dieser Substanzen auf andere gleichartige Tiere (Hühner). Aber auch das auf diese übertragene Affen- und Menschenpoliomyelitisvirus blieb unwirksam. Eine Empfänglichkeit dieser Tiere für das Poliomyelitisvirus war demnach nicht nachweisbar, wie überhaupt nach den Untersuchungen der meisten Forscher andere Tiere wie Affen sich sehr refraktär gegen das Gift zeigten. Auch auf die mögliche Übertragung von Kinderlähmung durch Insekten gerichtete Versuche hatten keinen sicheren Erfolg. Ausnahmsweise ließen sich Infektionen durch mit Virus gefütterte Fliegen (Musca dom.) oder Wanzen und Stallfliegen (Stomoxys calcitrans), die zuerst Poliomyelitisaffen gestochen hatten, feststellen, während die Versuche mit Stechmücken (Anopheles) negativ waren. Die Möglichkeit einer direkten Ubertragung durch Insekten vom Körper oder den Beinen aus infolge von Verschleppung der Krankheitskeime scheint demnach vorzuliegen. Aber ganz ausgeschlossen ist es, daB diese Insekten als Zwischenwirte unter Annahme eines Entwicklungsganges auBerhalb des menschlichen oder tierischen Körpers, wie wir es z. B. bei der Malaria sehen, in Betracht kommen.

Auch für die Immunitätsforschung und künstliche Immunisierung, demnach für eine rationelle Behandlung der Kinderlähmung, eröffneten sich Aussichten. Konnte doch durch französische Forscher (Netter, Gondron und Touraine) im Jahre 1911 nachgewiesen werden, daB die intraspinale Injektion von Serum, das von Menschen stammt, die an dieser Krankheit erkrankt waren, die weitere Ausbildung der Erkrankung zu hemmen vermochte (passive Immunisierung). Thomsen konnte Affen durch subkutane Injektion von genau bekanntem Virus soweit immunisieren, daB sie später die 100 fache, tödliche Dosis intrazerebral ganz gut vertrugen. Die Untersuchungen über die Natur des Poliomyelitisvirus ergaben bis dahin, daB es bakteriendichte Filter passiert, sich in Glyzerin lange wirksam hält, gegen niedrige Temperaturen unter $0^{\circ}$ und gegen längere Austrocknung wenig empfindlich, gegen Temperaturen über $50^{\circ}$ dagegen sehr empfindlich ist, also in vielen Beziehungen dem Erreger der Tollwut ähnelt. Die tödliche Dosis des Filtrates für Affen soll nach 
Flexner und Lewis 0.01 bis 0.001 betragen. Von Desinfeltionsmitteln töteten Kaliumpermanganat und Wasserstoffsuperoxyd (Perhydrol) in 2 bis 5 prozentiger Lösung in 1 Stunde das Gift ab; Mentholpräparate und Formaldehyd verhielten sich angeblich ebenso, was vielleicht für eine persönliche Prophylaxe wichtig erscheint.

Das Endglied der bakteriologischen Erforschung der Poliomyelitis scheint nun gefunden zu sein, als im Jahre 1913 nach vorangegangenen ähnlichen Versuchen zwei berühmte Forscher des RockefellerInstitutes, Flexner und Noguchi, den Mikroorganismus dieser Krankheit bakteriologisch und auch kulturell nachweisen konnten. Sie züchteten auf speziell angegebenen Nährböden (Aszitesflüssigkeit mit einem Stückchen sterilen Tiergewebes) unter SauerstoffabschluB bei Bluttemperatur aus dem Gewebe von an Poliomyelitis erkrankten Menschen und Affen besonders kleine, runde Mikroben, die im Dunkelfeld und nach Giemsa. und Gram gefärbt in kurzen Ketten, Paaren oder Konglomeraten zusammenhingen, durch Porzellanfilter gingen und die auf $A f f e n$ überimpft in klinischer und pathologisch-anatomischer Beziehung (in einem Stamm bis zur 20. Generation' noch) eine richtige Affenpoliomyelitis hervorriefen. Bei intrazerebraler Injektion des Kulturmaterials verbreiteten sich diese Mikroorganismen sehr schnell über das ganze Zentralnervensystem und konnten kulturell von dort aus überall nachgewiesen werden. Auch in Ausstrichpräparaten von infiziertem Gewebe, sowie in Schnitten wurden sie zwischen den Zellen und Nervenzellen liegend in Paaren oder Gruppen angeordnet vorgefunden. Desgleichen gelang die Züchtung auch im festen Nährsubstrat (Aszitesagar). Die verschiedenen Kulturstämme erwiesen sich nun für Affen verschieden pathogen. Einige konnten gleich Affenpoliomyelitis hervorrufen, andere muBten erst durch Tierpassagen ihre Virulenz erhöhen.

\section{Epidemiologie.}

$\mathrm{DaB}$ die Heine-Medinsche Krankheit als eine spezifische, durch einen bestimmten Erreger bedingte Infektionskrankheit aufzufassen ist, daran kann nunmehr nicht gezweifelt werden, desgleichen nicht daran, daB die Ubertragung in den weitaus meisten Fällen von Menseh zu Mensch erfolgt. Nach Wickmann knüpft jeder Fall an einen anderen an, sei es direkt oder indirekt (Bazillen- oder Keimträger). Seine sorgfältigen Studien zeigen uns, wie sich die Epidemien längs der Verkehrswege ausbreiten und kleinere und größere Herde und Inseln bilden, die dann wieder die Krankheit in anderer Richtung verschleppen können und zwar in der Art, daB immer ein Zusammenhang, unter Berücksichtigung der typischen und abortiven Fälle, sowie gesunder Zwischenträger, zu konstruieren ist. Diese Beobachtungen werden nun im allgemeinen von 
allen Forschern anläBlich der Epidemien in Europa und Amerika bestätigt. Auch gelegentlich der Epidemie in Hessen-Nassau konnte durch Müller neben der Weiterverbreitung der Krankheit durch gesunde, erwachsene Zwischenträger festgestellt werden, daB weniger die seßhafte Bauernbevölkerung beteiligt war, als vielmehr Gewerbetreibende, wie Gastwirte, Kutscher, Briefträger, Arbeiter mit Bahnfahrt und besonders Schuhmacher (Übertragung durch den Schmutz der Schuhe - Eichelberg). Prof. Trumpp beschrieb drei Geschwistererkrankungen einer Familie Münchens innerhalb dreier Monate während der zweiten Hälfte des Jahres 1912, wo die Ansteckung durch Kontakt erfolgte. Auch sonst wurden Geschwistererkrankungen ron einzelnen Beobachtern recht häufig festgestellt. In der Abteilung für luetische Kinder des GroBen-Friedrichs-Waisenhauses zu Berlin erkrankten im Herbst 19135 ron 22 Kindern an typischer Heine-Medinscher Krankheit, also eine Anstaltsendemie, die wahrscheinlich durch auswärtige Besucher eingeschleppt, nur durch strenge Isolierung zurückgehalten werden konnte. Wenn trotzdem in einzelnen Epidemiegegenden (New-York, Wien) kein Beweis für eine sonderliche Kontagiosität erbracht werden konnte, so lag das daran, daB in dicht bevölkerten Industriegegenden und großen Städten mit fluktuierender Bevölkerung ein Nachweis des Zusammenhanges und zumal desjenigen durch abortive Fälle und Keimträger sehr schwer zu erbringen ist. So konnten auch während der Epidemie im nördlichen Teil des GroBherzogtums Baden im Jahre 1913, wo allein 71 Fälle die Heidelberger Kinderklinik aufsuchten, nur 6 direkte Kontaktfälle nachgewiesen werden; in 28 von diesen Fällen war auch keine indirekte Ubertragung erweislich. Die Ansteckungsmöglichkeit scheint danach keine sonderlich hohe zu sein; wenn man diejenige für Scharlach zu 22 Prozent, diejenige für Diphtherie zu 17 Prozent berechnet, so ist die für Poliomyelitis auf höchstens 6 Prozent zu schātzen. Weiter lehrt die Statistik, daB die Verschleppung der Epidemie unabhängig von der Dichte der Berölkerung ist, und daB sogar in kleinen Städten und auf dem Lande die Kinderlähmung häufiger auftritt, wie in großen Verkehrszentren und in dicht bevölkerten Gegenden. Im allgemeinen bevorzugt die Kinderlähmung die heiße Jahreszeit (Sommer und Frühherbst) zu ihrem Auftreten, wie sich dies in den einzelnen Epidemien zeigt. Während dieser wurden nun vereinzelte Erkrankungen beobachtet, in denen die Krankheit mit anderen Infektionskrankheiten kombiniert war oder sich im Verlaufe von den Körper schwächenden Allgemeinerkrankungen entwickelte, die dann nur als begünstigendes $\mathrm{Mo-}$ ment aufzufassen waren. Eine Prädisposition existiert nach den Untersuchungen aller Beobachter überhaupt nicht; kräftige und gesunde Kinder erkranken gerade so oft, wie schwächliche. Auch spielt das Geschlecht 
der Erkrankten, sowie der Beruf und die Lebensstellung der Eltern keine sonderliche Rolle. Nur bezüglich des Lebensalters hat es sich nach der Statistik herausgestellt, daB besonders die Kinder erkranken, und hier wieder am meisten diejenigen im Alter ron 1 bis 3 Jahren, wobei das zweite Lebensjahr bevorzugt wird. Das jüngste erkrankte Kind der westfälischen Epidemie war 1 Monat alt. Aber auch ältere Personen über 20 Jahre werden befallen. Die Statistik lehrt aber auch, daB die Krankheit keinesfalls an besonders ärmliche und unhygienische Verhältnisse der Wohnungen gebunden ist, Kinder der besser situierten Klassen erkranken nahezu ebenso oft, wie Ablömmlinge von Proletariern. Während der rheinisch-westfälischen Epidemie im Jahre 1909 konnten speziell ron Kreisarzt Dr. Wollenweber-Dortmund -viele abortive Erkrankungen im .Reg.-Bez. Arnsberg beobachtet werden, die unter dem Bilde der Ruhr verliefen und keine Lähmung hinterlieBen.

Nach Häufung ron Fällen im Jahre 1908 (Heidelberg, Hamburg) wurde in Deutschland seit Frühjahr 1909 zunächst ein epidemisches Auftreten ron Kinderlähmung im rheinisch-vestfälischen Industriebezirk, anscheinend ausgehend von einigen Gruppenerkrankungen in Hagen und Umgebung, die angeblich von schwedischen Ingenieuren eingeschleppt waren, beobachtet. Die Epidemie verbreitete sich schnell (über 700 Erkrankungen) und griff dann im August auch auf die Provinz Hessen-Nassau über, von da auf Oberhessen und spāter auf die südlichen Kreise der Provinz Hannover. Ihr folgten dann in den Jahren 1910 bis 1912 Epidemien in Pommern (Reg.-Bez. Stettin und Stralsund), in den südlichen Kreisen von Schleswig-Holstein und diejenige in Schlesien mit dem Mittelpunkt in Breslau. Kleinere Herde zeigten sich in Berlin und Umgebung (1910), sowie in München und Vororten (1912), von wo aus ein epidemisches Auftreten in Bayern konstatiert werden konnte (im ganzen 197 Fälle). Im Frühjahr 1913 fand ein weiteres, stark gehäuftes Auftreten im nördlichen Teil des Großherzogtums Baden mit Heidelberg im Zentrum und Ausstreuungen im Königreich Württemberg (Oberamt Wangen) statt. Von dort aus griff die Seuche seit Anfang April und Mai desselben Jahres auch auf die südlichen Provinzen des Großherzogtums Hessen, speziell auf Starkenburg und Rheinhessen und auf einzelne Kreise der Propinz Oberhessen über. Nach Schätzungen werden im ganzen Deutschland während der Jahre 1908 bis 1914 weit über 1500 Personen erkrankt seiv.

\section{Die Epidemie im Großherzogtum Hessen während der Jahre 1909 bis 1914.}

Beschaffung und Würdigung des Materials. Das Material, aus welchem die im Großherzogtum Hessen gemachten Erfahrungen zu- 
sammengestellt wurden, stammte aus den monatlich einzusendenden Epidemieberichten der Kreisgesundheitsämter. Zudem wurde anläBlich des gehāuften Auftretens in Oberhessen im Jahre 1909 unter Bezugnahme auf die Beratung des Kaiserlichen Gesundheitsamtes in Berlin Ende Oktober und auf eine Besprechung der interessierten Kreisärzte im hygienischen Institut zu GieBen Ende November desselben Jahres hin, sowie anläBlich der ersten Fälle im Kreise Worms im Jahre 1913 durch eine Verfügung des Großh. Ministeriums des Innern, Abteilung für öffentliche Gesundheitspflege vom 4. August 1913 allen Kreisgesundheitsämtern eine sofortige Berichterstattung mit Erhebung an Ort und Stelle zur Pflicht gemacht. Zu gleicher Zeit wurde für einzelne Kreise, in denen bis dahin die Kinderlähmung nicht $\mathrm{zu}$ den anzeigepflichtigen Krankheiten gehörte, die Aufnahme derselben in die Polizeiverordnung, betreffend die Bekämpfung ansteckender Krankheiten, seitens der zuständigen Kreisämter angeordnet. Die Anzeigepflicht seitens, der behandelnden Arzte bzw. Haushaltungsrorstände war somit gewährleistet. Das auf diese Art gesammelte Material wurde nun nach den einzelnen Kreisen und Jahrgängen gesichtet, durch umfangreiche Nacherhebungen und durch Rückfragen bei den beamteten Ärzten und praktischen Arzten ergänzt und so statistisch verwertet. Wenn man nun auch wahrscheinlich annehmen muB, das manche leichte Erkrankungen an Kinderlähmung, speziell die abortiven Fälle, schon aus dem einfachen Grunde, weil sie nicht in ärttlicher Behandlung standen oder von den Angehörigen übersehen wurden, nicht angezeigt wurden, somit bei unserer Berechnung nicht mitzählen, so ergibt doch diese $\mathrm{Zu}-$ sammenstellung aller im Großh. Hessen während der letzten 5 Jahre gemeldeten Erkranknngen ein gutes Bild über den klinischen Verlauf, den Ausgang der Krankheit (Mortalität), sowie über die ätiologischen oder epidemiologischen Verhältnisse.

\section{Zusammenstellung \\ der einzelnen Erkrankungen nach Provinzen, Kreisen, Gemeinden und Jahrgängen geordnet.}

\section{Provinz Oberhessen.}

Kreis Alsfeld.

Wahlen (460 Einwohner).

1. Elisabeth St., 3 Jahre alt, Vater Landwirt, krank seit Mitte Juni 1909, hohes Fieber, Halsentzündung, Nacken- und Rückensteifigkeit, Lähmung des rechten Arms. Nach 5 Jahren noch Parese der rechten Daumenmuskeln. Frau St. war im März 1909 in Westfalen in einer Gegend, wo angeblich Kinderlähmung herrschte. 
2. Ernst R., 3 Jahre alt, Vater Landwirt, erkrankte im Juli 1909 plötzlich an Fieber, Verstopfung und Harnverhaltung, sowie an Lähmung der Beine. Nach 2 Jahren völlige Genesung.

3. Bertha Sch., 2 Jahre alt, Vater Landwirt, krank seit Ende August 1909, Fieber, Verstopfung, Harnverhaltung, Nacken- und Rückensteifigkeit, Lähmung des linken Beins. Nach $4^{3} / 4$ Jahren zurückgeblieben, leichte Parese des linken Unterschenkels, sekundäre Kontraktur der Wadenmuskeln, pes equinovarus.

4. Frau K. Pf., 26 Jahre alt, Ehemann Landwirt, erkrankt seit 29. IX. 1909. Nacken- und Rückensteifigkeit, Lähmung des rechten und dann des linken Arms, Sprachstörung, Gaumensegellähmung. Nach 4 $3 / 4$ Jahren noch starke Atrophie und Parese der Schultermuskulatur beiderseits, Muskelschwund in beiden Armen und Händen (Musc. interossei). FaustschluB rechts nur zur Hälfte möglich.

Nieder-Ofleiden (460 Einwohner).

1. Wilhelm M., $3 / 4$ Jahr alt, Vater Landwirt, krank seit Mitte November 1909, Lähmung des linken Beins. Nach $3^{3} / 4$ Jahren noch geringe Verkürzung und erhebliche Schwäche des linken Beins, besonders am GesäB und Oberschenkel.

2. Konrad M., 3 Jahre alt, Bruder des vorigen, krank seit Mitte November 1909, Lähmung des linken Beins. Nach $4^{3 / 4}$ Jahren noch Schwäche des linken Beins, geringe Spitzfußstellung und bajonettförmige Stellung der Zehen.

3. Knabe $X ., 1^{1} / 2$ Jahre alt, Vater Landwirt, krank seit Fnde November 1909, Fieber, Erbrechen, Durchfall. Abortivform.

Die Fälle in Wahlen und Nieder-Ofleiden sind auf Ansteckung aus den benachbarten preuBischen Orten (Kirchhain und Umgebung) zurückzuführen.

Arnshain (440 Einwohner).

1. Knabe Pl., 3 Jahre alt, Vater Straßenwärter, krank seit November 1910, Lähmung des linken Beins. Nach $3 \frac{3}{4}$ Jahren noch Lähmung des linken Beins mit Atrophie und SpitzfuBstellung, trägt Schienenhülsenapparat.

2. Kind Hrch. M., 2 Jahre alt, Vater Landwirt, krank seit September 1912, Lähmung beider Beine. Nach etwa 3 Jahren noch Parese des linken Beins, Lähmung des Quadriceps, Spitzfußstellung.

Nieder-Gemünden (550 Einwohner).

6 jährige Tochter dea Lehrers K., krank seit dem 21. VI. 1911, Magendarmerkrankungen, dann Lähmung des rechten Beins, gleichzeitig Masernerkrankung, Nach 3 Jahren noch starke Parese.

Lehrbach (330 Eimwohner).

2 jähriges Kind, Vater ist Kutscher, rechtsseitige Peroneusparese und Augenmuskellähmung, krank seit 17. VIII. 1913. Völlige Heilung.

Maulbach (430 Einwohner).

6 jähriger Knabe, Vater ist Landwirt, krank seit Mitte September 1913, meningitische Reizerscheinungen; völlig genesen. 


\section{Kreis Giessen.}

Gieben (31500 Einwohner).

Lina Sch., 4 Jahre, Vater Gendarmerie-Wachtmeister, erkrankt am 23. IX. 1909 mit Fieber, Kopfweh, Verstopfung. Am 25. IX. Lähmung des rechten Armes und der Beine. Vom 27. IX. bis 6. X. in der medizinischen Klinik zu GieBen. Nach $4 \frac{1}{2}$ Jahren noch Lähmung der Schulterblattmuskulatur und des Deltamuskels rechts.

Garbenteich (870 Einwohner).

1. Helene St., 3 Jahre alt, Bahnbeamtentochter in Garbenteich, erkrankte am 15. X. 1909, Genickschmerzen, Fieber, starker Schweib und Kopfweh, Lähmung, beider Beine, der Arme und des Rumpfes, gestorben am 19.X. Typische Erkrankung.

2. Hans St., 2 Jahre alt, Bruder der vorigen, krank seit dem 16.X.1909, Fieber, Schmerzen in beiden Beinen, Lähmung der rechten Seite und des linken Beins, Lähmung des rechten Arms besteht noch nach 10 Wochen. Die Mutter war mit beiden Kindern vom 4. bis 10 . X. in Niederwetter bei Marburg, also in durchseuchter Gegend, zu Besuch. Typischer Fall. Später ausgeheilt.

3. Anna B., 3 Jahre alt, Straßenwärterstochter in Garbenteich, krank seit dem 25. X. Fieber, leichte Halsentzündung, einmal Erbrechen, Lähmung beider Beine und des einen Arms. Am 27.X. Tod unter Erscheinungen von Atemlähmung. Typischer Fall. Die Mutter war bei der Beerdigung des Kindes 1. im Sterbehaus.

4. Otto Br., $1^{1 / 3}$ Jahre alt, Tagelöhnerkind in Garbenteich, erkrankte am 7. XI. an Durchfall und Erbrechen mit Fieber. Lähmung beider Beine, bemerkt am 12. XI. Typische Erkrankung. Die Mutter geht in dieselbe Zigarrenfabrik, wo die Mutter des unter 3. verstorbenen Kindes auch arbeitet. Nach $4^{1} / 2$ Jahren noch Lähmung des Peroneus rechts.

5. Franz Sch., ${ }^{3} / 4$ Jahre alt, Kind des Pächters der Wasenmeisterei bei Garbenteich, krank seit dem 17. XI., Durchfall und Erbrechen, Fieber, Schweib, Lähmung der Hals- und Schultermuskeln (Nervus recurrens). Typische Erkrankung. Der Vater des unter 3. verstorbenen Kindes war am 13. XI. mit den Eltern dieses Kindes zusammen. Später ausgeheilt.

6. Heinrich Sch., 3 Jahre alt, Bruder des vorigen, erkrankte ebenfalls am 17. XI. unter den Erscheinungen von Gastroenteritis, Fieber, Durchfall und Erbrechen, stark riechende-Stuhlentleerung; nach 2 Tagen Besserung, so daß das Kind nach Frankfurt zu den GroBeltern gebracht wurde. Abortivform von Kinderlähmung. Völlige Genesung.

7. Heinrich G., $1^{3} / 4$ Jahre alt, Tagelöhnerskind in Garbenteich, krank seit dem 27. XI., Fieber, Sensorium getrübt; am 29. XI. Tod unter Erscheinungen von Atemlähmung (Nervus phrenicus). Typischer Fall. Der Vater geht mit dem Vater des unter 4. erkrankten Kindes in eine Fabrik.

8. Elisabeth W., 3 Jahre alt, Tagelöhnerskind in Garbenteich, erkranktè am 29. XI. unter hohem Fieber, starkem SchweiB und Erbrechen. Des anderen Tags Wohlbefinden. Abortivform von Kinderlähmung. Die Mutter geht in eine Zigarrenfabrik in dem nahen Hausen, wo auch die Mutter des unter 7. verstorbenen Kindes arbeitet. Völlige Genesung. 
Lollar (2100).

Karl M., 2 Jahre alt, Vater Rangierer, erkrankte am 18. XI. 1909 an Magenschmerzen, geringes Fieber. Am 21. XI. Lähmung aller Extremitäten. Gestorben am 27. XI. in der Klinik. Sektionsergebnis: makroskopische Blutung in beiden Vorderhörnern des Rückenmarks.

Klein-Linden (1800 Einwohner).

1. Gustar B., 8 Jahre alt, Sohn einer Tagelöhnerin, erkrankte am 3. XI. 1909. Vom 10. XI. in der medizinischen Klinik, doppelseitige Fazialisparese, später Stottern. Rechtsseitige Fazialisparese noch nach $4 \frac{1}{2}$ Jahren geblieben.

2. Martin L., 4 Jahre alt, Sohn eines Arbeiters, krank seit Mitte Juni 1910. Gestorben am 30. VI. 1910 unter Erscheinungen der Landryschen Paralyse:

Wieseck (3200 Einwohner).

1. Emilie Kl., $3^{1 / 2}$ Jahre alt, Vater Maschinenputzer, krank seit dem 20. XI. 1909 an Fieber, Kopfweh, Durchfall und Erbrechen mit anschlieBender Lähmung der Hals-, Rücken- und Bauchmuskulatur, später Lähmung der Beine. Nach $4^{1} / 2$ Jahren noch Lähmung der Beine, muB zur Schule gefahren werden.

2. Emma R., $3^{1} / 2$ Jahre alt, Vater Tagelöhner, krank seit dem 9.XII.1909, Durchfall, Erbrechen, Kopfschmerz. Gestorben am 16. XII. 1909 unter Erscheinungen der. Bulbärparalyse. Die Mutter arbeitet in derselben Fabrik, wo die Mutter des Kindes sub 1 arbeitet.

3. Otto H., 3 Jahre alt, Vater Tagelöhner, krank seit dem 11: XII. 1909, Lähmung des linken Beins, Magendarmerscheinungen, auch Grimassieren. Später halbseitige Lähmung links. Trotz Operation (Dr. Zinßer, Gießen) Lähmung geblieben, besserer Gang.

Daubringen (820 Einwohner).

1. Marie G., $1^{3} / 4$ Jahre alt, Vater Fabrikarbeiter, krank seit dem 3. I. 1910 (Schnupfen, Katarrh). Linker Arm und linkes Bein gelähmt. Lähmung geblieben. Kontaktinfektion durch die Großmutter des am. 27. XI. 1909 verstorbenen Kindes Moos zu Lollar, die viel in der Familie Göbel verkehrte (Keimträgerin).

2. Ludwig Z., $13 / 4$ Jahr alt, Kind einer Witwe, krank seit dem 7. I. 1910. Infektion durch die Mutter des Kindes sub 1., die dem Kinde zu essen gab. Lähmung beider Beine; hatte vor der Erkrankung eine Rippenfellentzündung, die eine Rippenresektion erforderte. Lähmung des linken Beins noch 4 Jahre geblieben.

3. Lina R., 11 Monate alt, Vater Hilfsrangierer, krank seit dem 5. I. 1910. Lähmung des linken Beins geblieben nach 4 Jahren. Kontaktinfektion durch die Mutter sub 1., die gegenüber wohnte und viel dort verkehrte.

Steinberg (etwa 1000 Einwohner).

Karl R., 7 Monate alt, Vater Ziegeleiarbeiter, krank seit dem 3. VIII. 1911, Lähmung aller Extremitäten und der Halsmuskulatur, liegt apathisch da, Patellarreflexe nicht auslösbar, Bauchdeckenreflexe erhalten, Pupillen reagieren. Tod am 8. VIII. 1911 (Landrysche, Paralyse). 
Lang-Göns (1700 Einwohner).

Wilhelm L., 5 Jahre alt, Vater Landwirt, krank seit Anfang Januar 1914, leichtes Fieber, Diagnose wurde auf Influenza gestellt. Mitte Januar Lähmungserscheinungen in beiden Beinen neben trophischen Störungen. Gebessert.

Dazu noch 3 Erkrankungsfälle aus der Provinz Hessen-Nassau, die in der Universitäts-Kinderklinik (Prof. Dr. Köppe) zu Gieben behandelt wurden:

1. Hubert Sch., 8 Monate alt, Vater Eisenbahnarbeiter, aus Dehrn bei Limburg, krank seit dem 13. IX. 1913. Lähmung des linken Arms und rechten Beins; ungebessert entlassen.

2. Johann Gr, 21/2 Jahr alt, Vater Tüncher aus Panrod, krank seit dem 22. IX. 1913, Lühmung der Hals- und Rückenmuskeln, des rechten Arms und rechten Fazialis. Mit Lähmung des rechten Arms und des Fazialis gebessert entlassen.

3. Anna R., 6 Jahre alt, Vater Arbeiter aus Gräfenwiesbach, krank seit dem 22. XI. 1913. Lähmung beider Beine und des rechten Fazialis. Gebessert entlassen.

\section{Kreis Friedberg.}

Butzbach (4600 Einwohner).

Heinrich Gr., 11 Jahre alt, Vater Schuhmacher, krank seit dem 17. XI. 1909, halbseitige Lähmung, Bulbärerscheinungen, kam nachher in die medizinische Klinik zu GieBen. Nach $4 \frac{1}{2}$ Jahren noch Parese des einen Beins, geistig defekt.

Bad Nauheim (5700 Einwohner).

Kind, 5 Jahre alt, Vater Schuldiener, krank seit dem 22. X. 1909. Lähmung des rechten Arms und Beins, kam später in das städtische Krankenhaus. Nach $4 \frac{1}{2}$ Jahren noch halbseitige Parese.

Friedberg (10 000 Einwohner).

Kind K., 5 Jahre alt, Vater Gensdarm, krank seit dem 20. IX. 1909. Lähmung des rechten Beins. Nach 41/2 Jahren noch teilweise Paresse.

Ossenheim ( 370 Einwohner).

Kind, 9 Monate alt, Vater Weichensteller, krank seit Anfang August 1913. Lähmung des rechten Arms. Noch Parese. - Um dieselbe Zeit machten die Hühner der Hofreite eine Erkrankung durch.

Nieder-Florstadt (1800 Einwohner).

1. Marie K., $1^{3} / 4$ Jahr alt, Vater Arbeiter, krank seit dem 25. XI. 1913, Parese des rechten Arms geblieben.

2. Karl Kr., 2 Jahre alt, Vater Arbeiter, krank seit dem 25. XI. 1913. Lähmung des linken Beins. Gebessert.

3. Lina D., 1 Jahr alt, Vater Spengler, krank seit dem 1. XII. 1913. Lähmung des rechten Beins. Gebessert.

Die 3 Fälle fallen zeitlich zusammen, aber nicht örtlich. Infektion der ersten Fälle wahrscheinlich aus dem nahen Ossenheim.

Staden (370 Einwohner).

Karl W., 11/4 Jahr alt, Vater Knecht, krank seit Mitte November 1913, angeblich Lungenentzïndung (?), nachher Lähmung des linken Arms. Nach 3/4 Jahren noch Parese des linken Arms. 


\section{Kreis Büdingen.}

Bleichenbach (750 Einwohner).

Elise W., 3 Jahre alt, Vater Schweizer, krank seit dem 15. XII. 1909, Lähmung des rechten Arms und des rechten Beins. Nach $4 \frac{1}{2}$ Jahren besteht noch Peroneus-Lähmung rechts. - Zwei Kinder desselben Hauses waren zur selben Zeit an Magendarmerscheinnngen mit Fieber erkrankt (Abortivform).

Stockheim (820 Einwohner).

Ottilie K., 3 Jahre alt, Vater Wagner, krank seit dem 24. VI. 1910. Lähmung des linken Beins. Nach $3 \frac{3}{4}$ Jahren besteht noch Peroneusparese links.

Bisses (280 Einwohner).

1. Junge Z, 4 Jahre alt, Vater Landwirt, krank seit Mitte September 1913. Lähmung des einen Beins. Gelähmt geblieben.

2. Mädchen, 8 Jahre alt, Vater Schmied. Lähmung aller Extremitäten und der Rumpfmuskulatur, krank seit dem 29. IX. 1913. Tod am 5. X. unter Erscheinungen der Landryschen Paralyse.

3. Junge von 9 Jahren, Vater Wirt, krank seit dem 5. X. 1913. Lähmung aller Extremitäten und der Rumpfmuskulatur. Tod unter Erscheinungen der Atemlähmung.

Alle drei Fälle wohnten in einer StraBe nicht weit voneinander und verkehrten miteinander, demnach Kontaktinfektion.

Wippenbaeh.

1. Kind von 3 Jahren, Vater Tagelöhner, krank seit Nitte September 1913. Lähmung beider Beine und teilweise des einen Arms. Es besteht noch Lähmung eines Beins.

2. Kind von 4 Jahren, Vater Landwirt, krank seit dem 13.X. 1913. Lähmung der gesamten Rumpfmuskulatur und aller Extremitäten. Gestorben am 15. X. unter zerebralen Erscheinungen.

Höchst a. d. N. (500 Einwohner).

Junge von 7 Jahren, Vater Sehuhmacher, krank seit dem 20. X. 1913. Lähmung des rechten Arms und rechten Beins. Tod nach 5 Wochen unter zerebralen Erscheinungen.

Bindsachsen (500 Einwohner).

Junge von 10 Jahren, Vater Weißbinder, krank seit Mitte Oktober 1913, Lähmung beider Beine, Amblyopie. Besserung.

\section{Kreis Lauterbach.}

Hörgenau (260 Einwohner).

1. Zweijährige Tochter des Posthilfsstellenverwalters, krank seit dem 28. III. 1910. Fieber, SchweiBabsonderung, Lähmung beider Beine und Arme. Tod am 10. IV. 1910 an Schlucklähmung.

2. Knabe von $4^{1 / 2}$ Jahren, Vater Lehrer, krank seit dem 29. VI. 1913, tonischer Krampfzustand der Gesichts- und Rückenmuskulatur, Fieber, profuse SchweiBabsonderung, starke Empfindlichkeit, Lähmung der Beine, Blasenund Mastdarmstörungen. Patellarreflexe orloschen. Später Rückgang der Lähmungen und völlige Heilung. 
Sickendorf (130 Einwohner).

Kind Sch., $1 \frac{11}{2}$ Jahr alt, Vater Milchfuhrmann, krank seit dem 7. XI. 1913, Verstopfung, Fieber, später Lähmung des linken Peroneus. Heilung.

\section{Kreis Schotten.}

Burkhards (480 Einwohner).

2 jährige Tochter des Pfarrers L., krank seit dem 30. IX. 1913, Fieber, Magendarmerscheinungen, später Lähmung des rechten Beines, kam in die Kinderklinik zu GieBen. Parese noch bestehend. - Infektion vielleicht durch den älteren Bruder, der im Kreise Erfurt wohnt und 14 Tage vor der Erkrankung zu Besuch nach Hause kam.

Ober-Seemen (960 Einwohner).

4 jährige Tochter des Landwirts L., krank seit Ende September 1913, Fieber, Überempfindlichkeit mit nachfolgender Lähmung des rechten Beines. Völlige Heilung.

Schotten (2200 Einwohner).

Karl Str., 4 Jahte alt, Vater Nachtwächter, krank seit Anfang Oktober 1913, Lähmung des linken Beines. Peroneuslähmung geblieben. Der linke FuB steht nach auBen rotiert, ataktischer Gang.

Eschenrod (500 Einwohner). Wilhelm D., 19 Jahre alt, beschäftigt bei der Dreschmaschine in Lang-Göns, krank seit dem 22. XI. 1913, Kopfweh, Fieber; am 30. XI. Lähmung des einen Beines, Harnverhaltung, Schluck-, Atem- und Sprachstörungen, Facialis- und Hypoglossuslähmung. Tod am 5. XII. (bulbäre Form).

Glashütten (440 Einwohner).

Minna E., 7 Monate alt, Vater Fabrikarbeiter, krank seit Ende Dezember 1913, Lähmung des einen Beines. Lähmung zum gröBten Teil geblieben.

Ober-Lais (550 Einwohner).

1. Albert S., 5 Jahre alt, Vater Landwirt, krank seit Ende Dezember 1913, Lähmung beider Beine. Geringe Parese beider Beine zurückgeblieben.

2. Albert Pf., 9 Monate alt, Vater Landwirt, krank seit dem 5. I. 1914, Lähmung des einen Beines. Parese geblieben, schleift das Bein nach.

3. Anna N., $2^{1 / 2}$ Jahre alt, Vater Zimmermann, krank seit dem 15. III. 1914 plötzlich unter starkem Fieber, Bronchitis. Auffallende SchweiBausbrüche oder Parästhesien wurden nicht beobachtet. Fieber hielt 3 Tage an, keine Benommenheit. Zeichen von Blasen- und Herzschwäche. Am 5. Tage rechtsseitige Peroneuslähmung, am 6. Tage linksseitige. Am 7. Tage vollständige schlaffe Lähmung beider Beine. Am 23. III. Parese des rechten Armes nachweisbar. Später Besserung.

\section{Provinz Starkenburg.}

Kreis Bensheim.

Lampertheim (11000 Einwohner).

1. Margarete N., 2 Jahre alt, Pflegekind im Marienkrankenhaus, hatte Anfang April 1913 eine Lungenentzündung, die ausheilte. Anfang (1. oder 2.) Mai Fieber und Lähmung der rechten Seite. Parese des rechten Armes und 
Beines noch bestehend, Die Möglichkeit, daß in dem von auswärts (Mannheim) stark frequentierten Krankenhaus Bazillenträger die Krankheit übermittelt haben, ist gegeben.

2. Anna K., 11/4 Jahre alt, Vater Fabrikarbeiter, Spitalstraße 15, krank seit dem 2. V. 1913, Lähmung des rechten Armes noch bestehend.

3. Bernhard W., 14 Monate alt, Vater Fabrikarbeiter, krank seit Mitte Mai 1913, Schnupfen, dann Lähmung beider Beine. Exanthem am Körper. Lähmung des rechten Beines noch bestehend, wohnt alte SchulstraBe 2 .

4. Johann Adam J., 11/2 Jahre alt. Vater Fabrikarbeiter, krank seit Ende (24.) Mai 1913, Lähmung des linken Beines noch bestehend, wohnt Pfarrgasse, 11.

5. Karl L., 5/ Jahre alt, Vater Gastwirt, Pfarrgasse 4, krank seit Ende Mai 1913, Lähmung der rechten Seite. Parese noch bestehend.

6. Karl R., 21/2 Jahre alt, Vater Bahnaspirant, LeopoldstraBe 6, krank seit Mitte Juni 1913, Mandelentzündung, Fieber, dann Lähmung des Nackens, des linken Armes und beider Beine. Hautausschlag. Heilung.

7. Adam Sch, 2 Jahre alt, Vater Fabrikarbeiter, Riesengasse, krank seit Ende Juni 1913, Fieber, Zuckungen und Lähmung beider Arme und* des linken Beines. Parese des linken Armes und Beines noch bestehend.

8. Marie G., 13/4 Jahre alt, Vater Fabrikarbeiter, Siegfriedstraße 15, krank seit Mitte Juni 1913, Lähmung beider Beine. Heilung.

9. Katharine L., 9 Monate alt, Vater Fabrikarbeiter, Siegfriedstraße, krank seit Anfang Juli, Lähmung der rechten Seite. Heilung. - Die Familien verkehrten angeblich miteinander.

10. Barbara Br., 10 Monate alt, Mutter ohne Beruf, RömerstraBe 120, krank seit dem 15. VII. 1913, Lähmung des linken Armes und beider Beine. Noch Lähmung des rechten Beines mit KlumpfuBstellung bestehend.

11. Adam Kr., 16 Monate alt, Vater Wirt, Ernst-Ludwigstraße 11, krank seit Anfang Juli 1913, Lähmung beider Beine, Fieber, Zuckungen, Lähmung des linken Facialis. Jetzt noch Facialisparese bestehend.

12. Theodor W., 4 Jahre alt, Vater Buchdrucker, Ernst-Ludwigstraße 21, krank seit dem 12. VII. 1913, Fieber, bewuBtlos, Zuckungen. Tod am 15. Juli (Landrysche Paralyse).

13. Im AnschluB hieran als Kontaktinfektion seit dem 23. VII. Schwester Anna, 1 Jahr alt, Mandelentzündung, Fieber, später Lähmung beider Beine. Parese des rechten Beines noch bestehend.

14. Im AnschluB an die Erkrankung sub 2. durch das Kind des Bruders Erkrankung der Charlotte G., 12 Monate alt, Vater Fabrikarbeiter, Sandstraße 26, krank seit Ende Juli 1913, Lähmung des rechten Beines, vorher Keuchhusten. Lähmung mit SpitzfuBstellung noch bestehend.

15. Anna V., 5 Monate alt, Vater Fabrikarbeiter, SteinstraBe 6, krank seit Ende Juli 1913, Lähmung beider Beine noch bestehend. Vorher rechtsseitige Coxitis. In den Familien 4, 6 und 11 sollen zur selben Zeit einzelne Geschwister an Magendarmerkrankungen gelitten haben (Abortivform).

Bensheim (9000 Einwohner).

1. Johanna F., $2^{1} / 2$ Jahre alt, Vater städtischer Arbeiter, Wormserstraße 62, krank seit dem 9. VI. 1913, Fieber, Katarrh, Lähmung des rechten Beines. Parese des rechten Beines noch zurückgeblieben. - Ob 
eine Hausiererin aus dem Kreise Worms, die öfter zu der Familie kam, als Infektionsquelle in Betracht kommt, erscheint zweifelhaft.

2. Im AnschluB hieran als Kontaktinfektion, da die Mutter des erkrankten Kindes, als sie zum Arzt das Kind brachte, mit der Mutter des anderen Kindes, das diese auf dem Arm trug, sprach, Erkrankung der Marie E., $1^{1} / 4$ Jahre alt, Vater Steinschleifer, Wormserstrabe 37, krank seit dem 17. Juni 1913, Fieber, Durcbfall, Zuckungen, Lähmung des linken Armes. Parese noch zurückgeblieben.

3. Im AnschluB hieran als Kontaktinfektion durch die gesunde, schulpflichtige Schwester des Kindes E., die das Kind in Abwesenheit der Mutter hütete, Erkrankung der Margarete L., 16 Monate alt, Vater Bahnarbeiter, Wormserstraße 41, krank seit dem 31. VII. 1913, plötzliches Erbrechen, Fieber, am 2. VIII. Zuckungen, später Lähmung beider Arme und des rechten Beines. Zurückgeblieben ist eine vollständig schlaffe Lähmung des rechten Armes mit starker Atrophie; von Zeit zu Zeit zerebrale Erscheinungen mit Fieber, Überempfindlichkeit und Zuckungen.

4. Knabe Pf., 5 Monate alt, Vater Fabrikarbeiter, Hauptstraße 75, erkrankte am 28. V. 1913 an meningitischen Symptomen, Lähmung des Rückens, Bauchs und des Nackens, am 17. VI. Peroneuslähmung. Am 5. VIII. Verschlimmerung, am 8. VIII. Tod (Bulbärparalyse).

5. Im AnschluB hieran durch die Beratungsstelle für Säuglingsfürsorge, wo das Kind nach seiner Lähmung noch hingebracht wurde, Erkrankung der Elise St., 21/2 Jahre alt, Vater Fabrikarbeiter, Erbacherstraße 11, krank seit Ende Juni 1913 unter Zerebralerscheinungen, so daB der Arzt die Diagnose auf Meningitis stellte, Lähmung beider Beine eben noch bestehend.

Nordheim (830 Einwohner).

Ernst W., 11/2 Jahre alt, Vater Fabrikarbeiter, ging vor der Erkrankung des Kindes nach Worms arbeiten, krank seit Anfang September 1913, Magendarmerscheinungen, Fieber, später Lähmung der rechten Seite. Parese des rechten Armes ist zuriickgeblieben.

GroB-Rohrheim (1900 Einwohner).

Marie A., 17 Monate alt, Vater Makler, krank seit dem 4. X. 1913 an Magendarmerscheinungen, am 6. X. Lähmung des einen Beines, die sich nach 10 Tagen wieder ganz, ausglich. - Vater war am 30. IX. in Lampertheim in verschiedenen Häusern.

Lorseh (5000 Einwohner).

Anna L., 16 Monate alt, Vater Tagelöhner, krank seit Mitte Oktober 1913, Fieber, Zerebralerscheinungen, Lähmung des rechten Beines, dann des Rückens und des linken Beines, später komplette Jähmung beider Beine. Parese beider Beine noch bestehend. - Der Vater arbeitete vor der Erkrankung des Kindes in Sandhofen und kam damals mit vielen anderen Erdarbeitern zusammien.

\section{Kreis Offenbach.}

Offenbach (76000 Einwohner).

1. Severin Pf., 11/2 Jahre alt, krank seit Ende April 1913, Vater Fabrikarbeiter, Lähmung beider Beine, wohnt Senefelderstrabe 46. Anscheinend Dauerlähmung. 
2. Philipp K., $1 \mathrm{Jahr}$ alt, Vater Portefeuiller, wohnt ebenfalls Senefelderstraße 46, krank seit Ende Mai 1913, Lähmung aller Extremitäten. Völlige Heilung.

3. Karl B., 31/2 Jahre alt, Vater Bohrer, wohnt Senefelderstraße 48, krank seit Ende Mai 1913, fast völlige Körperlähmung. Zurzeit noch Peroneusparese rechts.

4. Knabe E., $4^{1} / 2$ Jahre alt, Vater Kesselschmied, krank seit Ende Mai 1913, wohnt Gustav-AdolfstraBe 37 (eine Querstraße der obigen). Lähmung beider Arme geblieben.

5. Hans R., 2 Jahre alt, Vater Fahrradhändler, wohnt Domstraße 4, krank seit Ende Juli 1913, Lähmung des linken Beines. Parese geblieben.

6. Erna Kl., 2 Jahre alt, Vater Postbote, wohnt KrafftstraBe 12, krank seit dem 3. IX. 1913, vorher verreist nach Böckingen i./W., wo damals keine Poliomyelitiserkrankungen vorlagen. Parese des linken Peroneus noch vorhanden.

7. J. B., 32 Jahre alt, Lehrer, wohnt Bismarckstraße 31, hatte Ende Dezember 1913 heftigen Magendarmkatarrh, Lähmungserscheinungen in den Beinen seit dem 12. I. 1914, dann in den Armen. Am Tage darauf vollständig schlaffe Lähmung aller Extremitäten und des Rumpfes. Sehnenreflexe erloschen. Nach 3 Wochen gingen die Lähmungen nach und nach zurück, zuletzt die der Rumpfmuskulatur. Nach 5 Monaten noch geringe Parese vorhanden. - In der betreffenden Schulklasse keine. Poliomyelitiserkrankungen nachweisbar.

\section{Obertshausen.}

Mädchen, $3^{1} / 2$ Jahre alt, Vater Arbeiter, krank seit Mitte Juli 1913, Lähmung beider Beine. Parese geblieben.

Egelsbach (3200 Einwohner).

1. Elise W., $3^{1} / 2$ Jahre alt, Vater Bahnschlosser, krank seit dem 7. VII. 1913, Lähmung beider Beine. Parese zurückgeblieben, trägt Stützapparat. - War in Thüringen zu Besuch und erkrankte dort.

2. Johannes Sch., 13 Jahre alt, Vater Gastwirt, krank seit dem 4. IX. 1913, Lähmung beider Beine. Heilung.

3. Therese H., $3^{1} / 2$ Jahre alt, Vater Fabrikarbeiter, erkrankte am 4. IX. 1913 auf der Reise in Markelsheim bei Mergentheim, wo angeblich Poliomyelitiserkrankungen vorkamen, Lähmung beider Beine mit genu-valgum-Bildung geblieben, trägt einen Stützapparat.

4. Die $4_{1 / 2}^{1 / 2}$ jährige Schwester hatte zur selben Zeit nur Erbrechen, Fieber, keine Lähmung (Abortivform).

5. Otto R., $3^{1 / 2}$ Jahre alt, Pflegekind, Pflegevater Schneider, krank seit dem 25. IX. 1913, Lähmung beider Beine und Arme. Tod am 1. $X$. in akutem Stadium. - Infektion durch das Kind sub 1, mit dem es manchmal verkehrte.

6. Heinrich E., $3^{3} \%$ Jahre alt, Vater Lackierer, krank seit dem 29. IX. 1913, Lähmung des linken und rechten Beines, besonders des rechten. Parese des rechten Beines geblieben. 


\section{Kreis Darmstadt.}

Darmstadt (88 000 Einwohner).

1. Knabe L., $1^{3} / 4$ Jahre alt, Mutter Witwe, Kahlertstraße, krank seit Anfang Juli 1913, Fieber, Erbrechen, Lähmung des reehten Beines und der Schulter, kam in das Krankenhaus. Gebessert.

2. Christian S., 2 Jahre alt, Vater Schreiner, Schuhknechtstraße, krank seit dem 28. VII. 1913, Lähmung der Beine. Gebessert.

3. Philipp G., 9 Jahre alt, Vater Maschinenmeister, Kranichsteinerstraße, krank seit dem 14. VIII. 1913, hohes Fieber, Rückensteifigkeit, Druckempfindlichkeit der Wirbelsäule, totale Lähmung beider Beine. Linkes Bein noch völlig gelähmt.

- 4. Ernst B., 2 Jahre alt, Vater Ingenieur aus Essen, zu Besuch Martinsstrabe, krank seit dem 11. IX. 1913, Lähmung aller Extremitäten. Die Eltern waren im Eleonorenheim einige Tage vorher, wo ein erkranktes Kind aus Arheilgen lag.

5. Alfred S., 7 Jahre alt, Vater Kaufmann, Schulstraße, krank seit dem 17. IX. 1913, leichte Parese der Beine. Völlige Heilung.

6. Irma Kl., 1 Jahr. alt, Vater Arbeiter, erkrankte im Eleonorenheim seit dem 21. IX. 1913, hohes Fieber, nach 5 Tagen Lähmung des linken Beines. Gebessert. - Infiziert duroh das Kind aus Arheilgen.

7. Mathilde Kl., 9 Jahre ail, Vater Eisenbahnarbeiter, Herrengartenstraße, krank seit dem 23. IX. 1913, geringe Lähmung eines Beines. Geheilt.

8. Hildegard H., 7 Jahre alt, Vater Kaufmann, Rheinstraße, krank seit dem 15. IX. 1913, Fieber, Lähmung des ganzen Körpers, am 18. IX. Tod (Bulbärparalyse). - Vater kam am 13. IX. von einer Geschäftsreise zurück.

9. Otto G., $1 / 2$ Jahr alt, Vater Kellner, Wienerstraße, krank seit dem 27. IX. 1913, Lähmung des einen Armes, Spitalpflege. Gebessert.

Arheilgen ( 6500 Einwohner).

1. Elise B., $1^{1} / 2$ Jahre.alt, Vater Eisenbahnbeamter, krank seit dem 10. VI. 1913, Lähmung des rechten Armes. Heilung. - Im Hause ging ein Schwein am 6. VII. ein, das 8 Tage an Krämpfen gelitten hatte.

2. August Sch., 1 Jahr alt, Vater Arbeiter, krank seit Anfang August 1913, Lähmung des einen Armes, kam am 20. VIII. in das Eleonorenheim nach Darmstadt. Gebessert.

3. Max V., 3 Jahre alt, Pflegekind, krank seit dem 5. VIII. 1913, leichte Fazialisparese links. Geheilt. - Wohnt in demselben Hanse wie 2.

Wixhausen (1800 Einwohner).

Frieda R., 11/2 Jahre alt, Vater Schlosser, krank seit dem 30. IX. 1913, Lähmung der Beine. Gestorben am 3. Oktober (Lundrysche Paralyse).

Eberstadt (7500 Einwohner).

Heinrich M., 3 Jahre alt, Vater Fabrikarbeiter, krank seit dem 4. IV. 1914, Lähmung der Beine. Gebessert. 


\section{Kreis GroB-Gerau.}

Nauheim (1740 Einwohner).

Peter S., 3 Jahre alt, Vater Landwirt, krank seit 1. VIII. 1913, plötzlich zusammengebrochen, Lähmung des rechten Beines. Parese des rechten Beines besteht noch.

Königstätten (1100 Einwohner).

Johs. H., 4 Jahre alt, Vater Landwirt, krank seit dem 1. VIII. 1913, Lähmung des rechten Armes. Dauerlähmung, Finger wenig beweglich.

Worfelden (970 Einwohner).

Wilhelm N., 3 Jahre alt, Vater Landwirt, krank seit dem 9. VIII. 1913, Lähmung des rechten Beines, Krämpfe. Gestorben am 31. VIII. (Bulbärsymptome).

Rüsselsheim (6000 Einwohner).

Anna K., 2 Jahre alt, Vater Fabrikarbeiter bei Opel, krank seit dem 8. XI. 1913, Lähmung des rechten Beines. Parese geblieben.

Bisch ofsh eim (4500 Einwohner).

Margarete L., 2 Jahre alt, Vater Kesselschmied in Mainz, krank seit dem 17. XI. 1913, Lähmung des rechten Beines und linken Armes. Parese geblieben.

Dornheim (1540 Einwohner).

Elise Kath. K., $3^{1} / 2$ Jahre alt, Vater Schuhmacher, krank seit Mitte Dezember 1913, Lühmung des rechten Beines. Parese geblieben.

Alle Erkrankungen hatten einen mehr schleichenden Verlauf, zeigten keine stürmischen Prodromalerscheinungen wie hohes Fieber und Nackenund Rïckensteifigkeit usw.

\section{Kreis Dieburg.} Reuscher.)

GroB-Umstadt (3750 Einwohner). (Mitteilung ron Dr. Gefe und

1. Kind St., 3 Jahre alt, Vater Fabrikarbeiter, krank seit dem 23. VIII. 1913, Lähmung des rechten Armes und der Halsmuskulatur. Tod am 27. VIII. (Landrysche Paralyse).

2. Elisabeth Fr., $1^{3} / 4$ Jahre alt, Vater Metzger, krank seit dem 24 . VIII. 1913, Erbrechen, Krämpfe, Lähmung der Halsmuskulatur, rapider Verlauf, am 25. VIII. Tod (Bulbärparalyse).

3. Im AnschluB an 1. durch Besuch der Mutter Fr.: Kind Fr., 51/2 Jahre alt, Vater Gastwirt (Kantine der Zuckerfabrik), erkrankte`am 4. IX. 1913 unter Magendarmerscheinungen, die am nächsten Tage noch anhielten. Am 7. IX. Fieber bis $38^{\circ}$, kann sich nicht aufsetzen, Schmerzen bei Berührungen. Am 13. IX. Lähmung aller Extremitäten. Kniescheibenreflexe erloschen, desgleichen Bauchdeckenreflexè. Die Lähmungen gingen nach und nach zurück. Parese des linken Beines geblieben. 
4. Kind Weber, 3 Jahre alt, Vater Landwirt, krank seit dem 4. IX. 1913 unter Erbrechen und Fieber, am 7. IX. meningitische Erscheinungen, ausgeprägte Nackensteifigkeit, Fieber bis $40^{\circ}$, das bald nachlieB, konnte sich nicht aufaetzen, Lähmung der Beine, Bauchdecken- und Patellarreflexe erloschen. Völlige Genesung. - In diesem Falle Übertragung durch die Tante der sub 5 und 6 genannten Kinder, die die Nachbarin von Webers ist.

5. Knabe V., 2 Jahre alt, Vater Sparkassenrechner, krank seit dem 25. VIII. 1913, fieberhafte Magendarmerscheinungen, Lähmung des linken Beines. Eben noch charakteristische Peroneuslähmung.

6. Im AnschluB hieran die Schwester V., 4 Jahre alt, krank seit dem 28. VIII. 1913, Lähmung der Arme, Beine und der Rumpfmuskulatur. Schwäche des rechten Beines zurückgeblieben.

7. Kind K., 5 Jahre alt, Vater Nachtwächter in der Zuckerfabrik, krank seit dem 12 IX. 1913, Magendarmerscheinungen, Lähmung der Bauchmuskeln, Beine, Urinverhaltung. Völlige Heilung. - Ansteckung durch die Kantine der Zuckerfabrik, wo der Vater verkehrte.

8. Kind H., 2 Jahre alt, Vater Buchdrucker, krank seit dem 17. IX. 1913, Magendarmerscheinungen, die lange anhielten, Lähmung des linken Beines. Völlige Heilung. Nachbarskind von vorigem.

9. Kind K., $1^{1} / 2$ Jahre alt, Vater Musiker, krank seit dem 20. IX. 1913, Lähmung beider Beine. Heilung. Nachbarskind.

10. Georg C., $1^{1 / 2}$ Jahre alt, Vater Gerichtsschreiber, krank seit dem 20. IX. 1913, Apathie, hartnäckige Verstopfung, Lähmung beider Beine und der Bauchmuskulatur, Geheilt. Nachbarskind.

11. Ältestes Geschwisterkind, 4 Jahre alt, krank seit dem .22. IX. 1913, nur Allgemeinerscheinungen, keine Lähmung.

12. Kind B., 4 Jahre alt, Vater Schuhmacher, krank seit dem 7. IX. 1913, Lähmong des linken Armes. Heilung.

13. Käthe T., 4 Jahre alt, Vater Fabrikarbeiter in der Zuckerfabrik, krank seit Ende September 1913, Parese des rechten Beines. Heilung. Vater verkehrte in der Familie $\mathrm{K}$.

14. Helene G., 4 Jahre alt, Vater Gastwirt, krank seit dem 24. VШ. 1913, Augenmuskellähmungen noch bestehend.

15. Bernhard $G ., 2$ Jahre alt, Vater Gastwirt, krank seit dem 27. VIII. 1913. Lähmung des linken Beines. Völlige Heilung.

16. Knabe F., $11 / 2$ Jahre alt, Vater Schuhmacher, krank seit dem 5.X. 1913, hartnäckige Verstopfung. Lähmung der Halsmuskulatur. Tod am 7. X. (Bulbärparalyse).

17. Nax M., 2 Jahre alt, Vater Glasermeister, krank soit dem 10. X. 1913, Magendarmerscheinungen, Urinverbaltung, Lähmung der Bauchmuskeln, Gleichgewichtsstörungen. Völlige Heilung. - Nachbarskind von $F$.

Nach Mitteilung von Dr. Ge fe erkrankten die Eltern K. (Nr. 7) 14 Tage nach Erkrankung ihres Kindes unter starkem Durchfall, Kopf- und Kreuzschmerzen (Abortivform). Bei Fr. (Nr. 3) erkrankten sämtliche erwachsene Angehörige $\mathrm{zu}$ derselben Zeit an fieberhaften Magendarmerscheinungen (Abortivform). Es erkrankten überhaupt damals im September trotz der kühlen Witterung viele 2- bis 3 jährige Kinder an Magendarmerscheinungen, einige in der Nähe von Erkrankten, eins in der Zuckerfabrik. 
Die Ginderhähmona im Grossherzogtom Hessen usw.

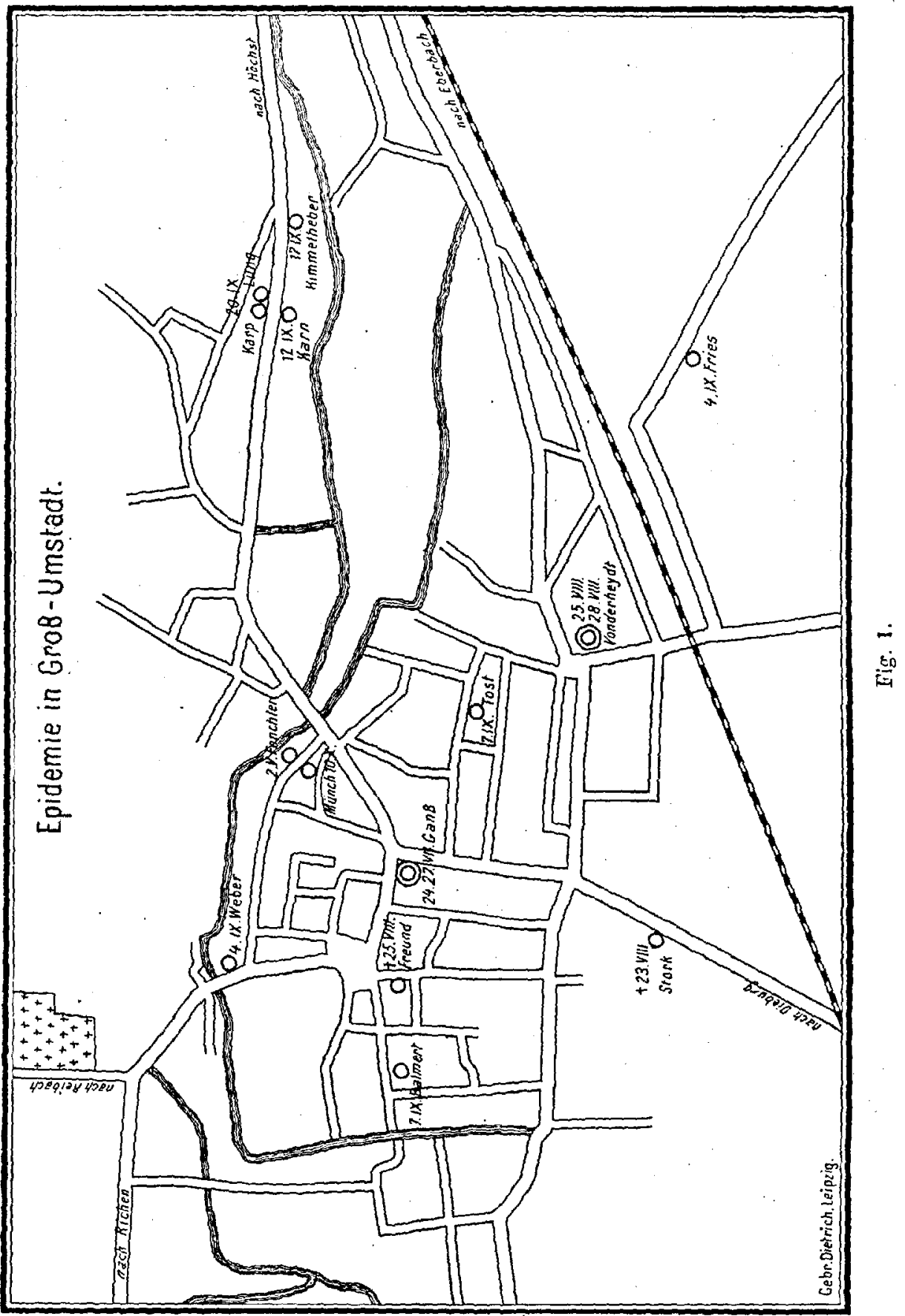


Hergershausen (725 Einwohner).

1. Wilhelm Kl., 21/2 Jahre alt, Vater Straßenwärter, krank seit dem 31. VIII. 1913, Lähmung aller Fxtremitäten. Lähmung des rechten Beines besteht noch.

2. Friedrich Kl., 3 Jahre alt, Vater Bäcker, krank seit dem 4. IX. 1913, Lähmung des linken Armes und beider Beine. Parese des rechten Beines geblieben. - Die GroBmutter infizierte durch Besuch bei 1. das zweite Kind.

3. Adam K., 4 Jahre alt, Vater Schlosser, krank seit Anfang September 1913, Lähmung des linken Armes und beider Beine. Geblieben ist Lähmung des rechten Beines und SpitzfuBstellung. - Häuser 1. u. 3. liegen schräg gegenüber.

Heubach (1100 Einwohner).

Adam S., 2 Jahre alt, Vater Steinhauer, krank seit dem 10. X. 1913, Allgemeinerscheinungen, Lähmung der Rumpfmuskeln und der Beine, ataktiseher Gang. Parese des linken Beines geblioben. (Lähmung der Adduktoren und Oberschenkelbeuger, Ataxie.) - Der Vater des Kindes hat in der fraglichen Zeit in GroB-Umstadt gearbeitet.

Raibach (450 Einwohner).

Katharina D., 5 Jahre alt, Vater Lumpensammler, krank seit Mitte Oktober 1913, Lähmung des linken Armes, Augenstörungen. Lähmung des Deltoideus links geblieben.

Grob-Bieberau (1900 Einwohner).

1. 3 jähriges Kind eines Kaufmanns, krank seit dem 11. IX. 1913, Angina, Gesichtslähmung, kam in das Krankenhaus nach Darmstadt. Linksseitige Fazialisparese noch bestehend.

2. 5jähriges Kind des Pfarrers, krank seit dem 24. IX. 1913, Angina, Lähmung des rechten Armes und linken Beines. Parese noch bestehend. Beide Kinder spielten zusammen.

\section{Kreis Heppenheim.}

Zotzenbach (900 Einwohner).

1. 2 jähriges Kind, Vater Tagelöhner, erkrankt im November 1910, Lähmung des einen Beines geblieben.

2. Knabe, 3 Jahre alt, Vater Fabrikarbeiter, krank seit dem 4. XI. 1913, Lähmung des rechten Armes. Genesung.

Neckar-Steinach (1700 Einwohner).

1. Helene. Sch., 10 Monate alt, Vater Schreiner, krank seit dem 18. VIII. 1913, vorausgehende Schmerzen im linken Hüftgelenk, spätere Lähmung des linken Beines. Parese des linken Beines geblieben. Infelktion aus dem nahen GroBherzogtum Baden.

2. Emma N., 3 Jahre alt, Vater Zimmermann, krank seit dem 31. VIII. 1913, Lähmung beider Beine, wurde 3 Wochen in der Luisenheilanstalt zu Heidelberg behandelt, Lähmung des rechten Beines geblieben.

Viernheim (9500 Einwohner).

1. Alexander H., 3 Jahre alt, Vater Buchdrucker, krank seit Mitte Juli 1913, Lähmung des linken Beines. Genesung. 
2. Marie S., 2 Jahre alt, Vater Maurer, krank seit Ende August 1913, Lähmung des rechten Beines, Blasenschwäche. Parese des rechten Beines geblieben.

3. Anna B., 11/2 Jahre alt, Vater Schuhmacher, krank seit Ende August 1913. Parese des linken Beines geblieben.

Wimpfen (3200 Einwohner).

Karl R., 11/2 Jahre alt, Pflegekind. erkrankt seit Mitte September 1913, Lähmung der Rückenmuskulatur und beider Beine. Parese der Beine geblieben. Infiziert aus dem nahen Baden.

\section{Kreis Erbach.}

Kailbach (108 Finwohner).

Mädchen, 2 Jahre alt, Mutter ohne Peruf, krank seit Ende August 1913, Lähmung des linken Armes. Parese noch bestehend. Wahrscheinlich Übertragung von dem benachbarten Friedrichsdorf (Baden), wo Fälle von Polio. myelitis vorkamen.

Günterfürst (330 Einwohner).

Knabe, 10 Monate alt, Vater Landwirt, krank seit Ende August 1913, Lähmung des linken Armes. Parese noch bestehend.

Schönnen (194 Einwohner).

Knabe, 10 Jahre alt, Vater Maurer, krank seit November 1913, Lähmung des ganzen rechten Armes. Dauerlähmung.

\section{3.- Provinz Rheinhessen. \\ Kreis Worms.}

Worms (47000 Einwohner).

1. Marie M., 10 Monate alt, Vater Schlosser, Worms-Neuhausen, krank seit Anfang Mai 1913, Lähmung aller Extremitäten. Gebessert.

2. Marg. Amalie H., 2 Jahre alt, Vater Heizer, krank seit Mitte Juli 1913, enzephalitische Erscheinungen. Tod am 27. VII.

3. Elise Weiske, 2 Jahre alt, Vater in Backsteinbrennerei, krank seit Mitte Juli 1913. Lähmung des linken Beines. Parese noch bestehend.

4. Hans W., 2 Jahre alt, Vater Pianist, krank seit Anfang Juli 1913, Lähmung des rechten Armes und Beines. Völlige Genesung.

5. Emma F., 3 Jahre alt, Vater Fabrikarbeiter, krank seit dem 10. VIIT. 1913, Lähmung beider Beine, im Krankenhaus behandelt. Parese der Beine besteht noch.

Horchheim (2400 Einwohner).

1. Christian W., $1^{3} / 4$ Jahre alt, Vater Fabrikarbeiter, krank seit Mitte Juli 1913, Lähmung des linken Quadriceps. Genesung.

2. Elisabeth K., $1^{3} /$ Jahre alt, Vater Landwirt, krank seit Mitte Juli 1913, Lähmung des rechten Fazialis. Heilung.

3. Marie S., $1^{3} / 4$ Jahre alt, Vater Fabrikarbeiter, krank seit dem 21. VII, 1913, Lähmung aller Extremitäten. Besserung. 
4. Heinrich Z., 1\%, Jahre alt, Vater Fabrikarbeiter, krank seit dem 23. VII. 1913, Lähmung beider Fazialis. Besserung. - Wohnt Nr. 1 nebenan.

5. Friedrich H., 2 Jahre alt, Vater Fabrikarbeiter, krank seit dem 26. VII. 1913, Lähmung des rechten Armes. Gebessert.

6. Katharina R., 11 Monate, Vater Fabrikarbeiter, krank seit Ende Juli 1913, Lähmung des rechten Quadriceps, Gebessert.

7. Fritz Kr., 14 Monate alt, Vater Maurer, krank seit dem 30. VII. 1913. Lähmung des rechten Beines. Gebessert.

8. Eva R., 8 Monate alt, Vater Fabrikarbeiter, krank seit dem 30. VII. 1913, Lähmung des rechten Quadriceps. Gestorben am 31. X. 1913 an Tuberkulose. Wohnt Nr. 1 gegenüber.

9. Valentin K., $1^{1 / 2}$ Jahre alt, Vater Landwirt und Bruder zu Nr. 2, krank seit dem 31. VII. 1913, Lähmung des rechten Beines. Geheilt. Wohnt neben Nr. 2.

10. Marie H., $1^{1} / 2$ Jahre alt, Vater Maurer, erkrankt Ende Juli 1913, Lähmung beider Beine. Geheilt.

11. Lina H., I Jabr alt, Vater Fabrikarbeiter, krank seit 7. VIII. 1913, Fieber $-38 \cdot 2^{\circ} \mathrm{C}$, belegte Zunge, Obstipation, Lunge und Sensorium frei, keine Lähmung. Am 8. VIII. normale Temperatur, auf Calomel reichliche Stuhlentleerung, leichte Apathie; ließ den Kopf leicht hängen, keine ausgesprochene Lähmungen, abends ganz munter, aB Suppe, trank Wasser. Um $4^{1 / 2}$ Uhr morgens am 9. VIII. plötzlicher Tod. (Siehe Plan zu Horchheim S. 106.) Sektion 12 Stunden später (Medizinalrat Dr. Schäffer): Nach dem Durchschneiden der Dura mater des Rückenmarkes flieBt eine größere Menge klare, hellgelbe Flüssigkeit aus (Odem). In der Gegend des Halsteiles des Rückenmarkes findet sich auf der Vorderseite der Dura Blut in dem Gewebe festsitzend, das sich nicht wegwischen. läBt. Das Gewebe ist dabei etwas sulzig. Auf der Hinterseite der Dura sind die Blutadern in der Zervikalgegend und in der unteren Hälfte des Rückenmarkes bis zur vollen Rundung mit Blut gefüllt, am Halsteil selbst die kleinsten GefäBe. Auf der Vorderseite der Dura sind die Gefäbe ebenfalls bis in die kleinsten Verzweigungen mit Blut gefüllt. Das Rückenmark ist an der Halsanschwellung auf der rechten Seite auffallend weich, gelbrötlich gefärbt, auf Durchschmitten über das Niveau vorquellend. Dieses Vorquellen ist noch bis in den Brustteil zu beobachten. Weiter nach unten ist die grave und weiße Substanz wieder deutlich voneinander zu unterscheiden. Das Gewebe fühlt sich daselbst auch härter an. Im Lendenmark ist das Gewebe überall gleichmäBig fest.

Hamm (1350 Einwohner).

1. Elise K., 2 Jahre alt, Vater Tagelöhner, krank seit Anfang Juni, Lähmung des Fazialis, schlaffer Gang. Gebessert.

2. Heinrich S., $2^{1} / 4$ Jahre alt, Vater Tagelöhner, krank seit Anfang Juli 1913, Lähmung des rechten Beines. Genesung.

Rheindürkheim (1300 Einwohner).

Hans R., $2^{3} / 4$ Jahre alt, Vater Heizer, krank seit Anfang Mai 1913, Lähmung beider Beine noch bestehend.

Osthofen (4200 Einwohner).

1. Elisabeth R., 4 Jahre alt, Vater Landwirt, krank seit Mitte Juli 1913, Lähmung beider Beine. Besserung. 
2. Ludwig E., 2 Jahre alt, Vater Sackträger, krank seit Mitte Juli, Lähmung beider Beine. Heilung.

3. Anna Kl,, 7 Jahre alt, Vater Lokomotivführer, krank seit dem 21. VII. 1913, Lähmung des linken Armes und rechten Beines. Heilung.

Bechtheim (1500 Einwohner).

1. Alfred S., 3/4 Jabre alt, Vater Landwirt, krank seit dem 12. VII. 1913, Lähmung beider Beine und des linken Armes. Tod am 17. VIII. (Landry sche Paralyse).

2. Lina R., 3 Jahre alt, Vater Tagelöhner, krank seit dem 20. VII. 1913, Lahmung des einen Beines. Gebessert.

A benheim (1660 Einwohner).

1. Marie Fl., 6 Monate alt, Vater Fabrikarbeiter, krank seit dem 26. VII. 1913, Lähmung des rechten Armes. Tod am 13. VIII. unter Zerebralerscheinungen.

2. Johann R., $\mathbf{1}^{3} /$, Jahre alt, Vater Fabrikarbeiter in Worms, krank seit Ende August 1913, Peroneuslähmung links ist geblieben.

Heppenheim a. d. W. (1500 Einwohner).

1. Heinrich Schm., $1 \frac{1}{2}$ Jahre alt, Vater Fabrikarbeiter, krank seit dem 9. VIII. 1913, Lähmung der Beine. Geheilt. - Spielte am 5. VIII. in Horchheim, wo die Epidemie herrschte, mit Kindern.

2. Heinrich Schw., 13 Monate alt, Vater Landwirt, krank seit dem 13. VIII., Lähmung des rechtẹn Armes. Tod am 16. VIII. unter Zerebralerscheinungen.

3. Balthasar A., 30 Jahre alt, arbeitete zusammen mit dem Fabrikarbeiter H. aus Horchheim Nr. 11, dessen Kind an Poliomyelitis starb, krank seit Anfang August an Serratuslähmung. Geheilt.

4. Im AnschluB hieran die Tochter desselben, Cäcilie A., $1^{3 / 4}$ Jahre alt, krank seit dem 1. IX. 1913, Lähmung beider Beine. Geheilt.

Gundheim (670 Einwohner).

Josefine R., 15 Monate alt, Vater Tagelöhner, krank seit dem 13.VIII.1913, Parese der linken unteren Extremität geblieben.

Herrnsheim ( 2400 Einwohner).

Anza B., 6 Jahre alt, Vater Schneider, krank seit dem 24. VIII. 1913, Lähmung des einen Beines. Gebessert.

Weinsheim (1000 Einwohner).

Rudolf S., 2 Jahre alt, Vater Tagelöhner, krank seit dem 24. VIII. 1913, Lähmung des linken Quadriceps. Heilung.

Gimbsheim (2700 Einwohner).

Johann K, 2 Jahre alt, Vater Händler, krank seit dem 16. IX. 1913, schlaffe Lähmung des rechten Beines. Gebessert.

\section{Kreis Bingen.}

Gaulsheim (750 Einwohner).

Elise H., 19/4 Jahre alt, Vater Kaufmann, krank seit Juni 1913, Lähmung beider Beine. Völlige Genesung. Infiziert von Lahr (Baden), wo die Krankheit damals herrschte. 
Bingen (10000 Einwohner).

1. Karl Hch. B., $3^{1} / 2$ Jahre alt, Vater Oberlehrer, krank seit dem 16. IX. 1913, Lähmung aller Extremitäten. Parese des linken Armes noch zurückgeblieben.

2. Karl Sch., 21/4 Jahre alt, Vater Gastwirt, erkrankt seit Mitte Oktober 1913, Lähmung des rechten Beines. Parese zurückgeblieben.

Büdesheim (3200 Einwohner).

Anna Sp., $1 \frac{1}{2}$ Jahre alt, Vater Fabrikarbeiter, krank seit September 1913 , Lähmung aller Extremitäten und der Harmblase. Lähmung der Beine noch vorhanden.

Alzey (8400 Einwohner).

\section{Kreis Alzey.}

1. Mädchen, 4 Jahre alt, Vater Schreiber, krank seit dem 1. VIII. 1913, Lähmung des linken Beines, hatte noch Masern dabei. Parese noch bestehend. - Die Mutter war vorher mit dem Kinde in Köln zu Besuch, dort wohl Infektion.

2. Knabe, 3/4 Jahre alt, Vater Kaufmann, krank seit Mitte August 1913, Lähmung beider Beine. Genesung. - Die Mutter arbeitete zusammen in einem Warenhause mit der Mutter des sub 1 genannten Kindes.

Wöllstein (1840 Einwohner).

Knabe, 21/2 Jahre alt, Vater Schneider, krank seit Mitte Oktober 1913, Lähmung des rechten Beines. Genesung.

Steinbockenheim (500 Einwohner).

Mädchen, $3^{1} /_{2}$ Jahre alt, Vater Landwirt, krank seit November 1913, Lähmung aller Extremitäten. Genesung.

\section{Kreis Mainz.}

Mainz (110600 Einwohner).

1. Kind, $3^{1 / 2}$ Jahre alt, Vater Chauffeur, krank seit dem 26. VI. 1913, erstes akutes Stadium, dann Lähmung der Hals-, Rücken-, Bein- und Gesichtsmuskulatur, auch Schlinglähmung. Tod am 30. VI. unter Erscheinungen der Atemlähmung.

2. Kind, 2 Jahre alt, Vater Landbriefträger, krank seit Anfang Juli 1913, Lähmung des linken Beines. Geringe Schwäche des linken Beines zurückgeblieben. - Die Eltern wohnten in benachbarten Häusern der Görtzschen Stiftung, und die Kinder besuchten dieselbe Kleinkinderschule, woselbst die anderen 36 Kinder gesund blieben.

3. Mädchen, 17 Jahre alt, bedienstet im Diakonissenheim, krank seit Mitte Juli 1913, schlaffe Lähmung der Beine. Nach 1 Jahr noch Parese des rechten und vollständige Lähmung des linken Beines, kann ohne zwei Krücken nicht gehen. - Wahrscheinlich Kontaktinfektion durch die Schwester der Görtzschen Kleinkinderschule, die sich im Diakonissenheim einige Tage aufhielt.

4. Kind, 8 Jahre alt, Vater Photograph, krank seit Mitte August 1913, Lähmung des linken Beines, kam am 27. VIII. in das Rochusspital. Nach 1 Jahr geringe Schwäche des Beines zurückgeblieben. 
5. Kaufmann W., 20 Jahre alt, krank seit Anfang August 1913, kam in das Rochusspital, Lähmung des rechten Beines. Nach 11 Monaten be. steht noch geringe Schwäche im Gebiete des rechten Ileopsoas, die keine Berufsstörung bedingt.

6. 11 jähriger Junge, Vater Arbeiter, krank seit Mitte November 1913, Lähmung des einen Beines. Geringe Parese zurückgeblieben.

\section{Kreis Oppenheim.}

Dexheim (730 Einwohner).

Karl D., 4 Jahre alt, Sohn einer Witwe, erkrankt Mitte August 1913, Lähmung des linken Armes und Beines. Dauerlähmung.

Guntersblum (2400 Einwohner).

Knabe, $1^{3} / 4$ Jahre alt, Vater Arbeiter in der Elektrizitätszentrale zu Osthofen, wo noch andere Arbeiter aus Worms und Osthofen arbeiteten, krank seit Anfang September 1913, Lähmung des rechten Armes. Gebessert.

Verdächtige Erkrankung eines Kindes 14 Tage vorher (Abortivform?)

Waller theim (1300 Einwohner).

1. Knabe, $1 \frac{1}{2}$ Jahr alt, Vater Knecht, krank seit Mitte September 1913, Läbmung des linken Beines. Genesung.

2. Mädchen, $1^{1} / 2$ Jahr alt, Vater Spengler, krank seit dem 20. September 1913, Lähmung des linken Beines. Genesung.

3. Knabe, $2^{1} / 2$ Jahr alt, Mutter Dienstmädchen, krank seit Mitte Oktober 1913, Lähmung beider Beine. Genesung.

Anfang September erkrankte ein 3 jähriges Kind fieberhaft, das aber nach 3 Tagen wieder gesund war (Abortivform?).

Was nun die klinischen Symptome der Erkrankungsfälle von Kinderlähmung im Großherzogtum Hessen während der letzten 5 Jahre anbelangt, so konnten wir auch die früher von sämtlichen Forschern betonten zwei Stadien unterscheiden (das der allgemeinen Infektion mit allen Begleiterscheinungen) und das Stadium paralyticum. Weist zeigten sich zu Beginn der Erkrankung Störungen von seiten des Magendarmkanals (Erbrechen, Durchfall, Leibschmerzen, Verstopfung). Nur 9 mal wurden auf die einzelnen Gegenden und Jahre regellos zerstreut Angina oder Katarrhe angegeben, wobei $\mathrm{zu}$ berücksichtigen ist, daB diese Symptome wohl in manchen Fällen nicht erwähnt wurden. In der weitaus gröBten Zahl der Erkrankungen wurde mäBig hohes Fieber beobachtet, in wenigen Fällen auch sehr starke Temperaturerhöhung, die nach einigen Tagen jedoch wieder zurücliging. Von seiten der Haut wurde in vielen Fällen auf eine profuse Schweißabsonderung hingewiesen; in manchen Fällen mag dies Kardinalsymptom jedoch übersehen worden sein. Hautausschläge konnten wir 2 mal konstatiert sehen. Kompliziert mit anderen Er- 
krankungen (Masern, Keuchhusten, Lungen- und Rippenfellentzündung, Coxitis) war die Poliomyelitis in 7 Fällen. Meningitische Reizsymptome im Prodromalstadinm (Zuckungen, Krämpfe; Benommenheit, Nackensteifigkeit) waren nicht sehr selten. Über Kopfweh wurde oft geklagt. Unter den sensiblen Reizerscheinungen wurde als zweiter Kardinalpunkt im Frühstadium die Überempfindlichkeit (Hyperästhesie) der Kranken sehr oft beobachtet. Von Blasen- und Mastdarmstörungen wurde 9 mal Erwähnung getan.

Im Stadium der Lähmungen konnten wir die spinale Form mit schlaffer Lähmung der Extremitäten weitaus am häufigsten feststellen: ron 208 Fällen, wobei die 3 Erkrankungen der GieBener Kinderklinik, die von Preußen stammen, mitzählen, allein 156 mal, während die zerebrale (enzephalitische, meningitische, Landrysche Paralyse, bulbäre) Form nur $44 \mathrm{mal}$ zu beobachten war. Meist entwickelten sich die Lähmungen allmählich; höchst selten setzten sie plötzlich auf einmal ein. Bei der Landryschen Paralyse wurde ausschlieBlich die aufsteigende Form erwähnt. Bezüglich der Verteilung der Lähmungen waren folgende Körperabschnitte beteiligt:

1. Lähmung eines Beins (Monoplegie) . . . . . . $58 \mathrm{mal}$

2. " beider Beine (Paraplegie) . . . . . . 40 ",

3. . " eines oder zweier Arme und eines Beins und umgekehrt (gekreuzte Lähmung oder

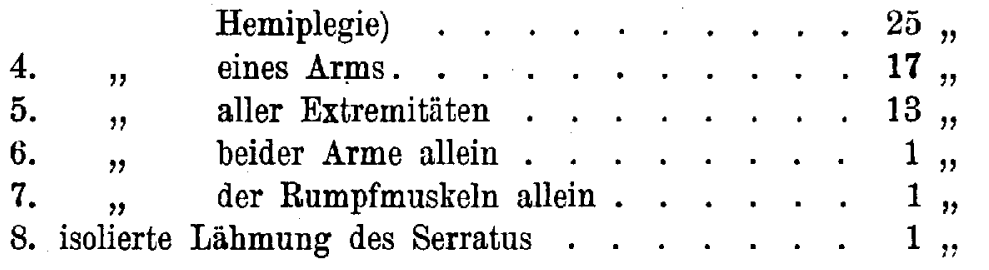

Die absolute Häufigkeit der einzelnen Extremitätenlähmungen entsprach demnach auch bei uns dem Bild der früher beschriebenen Epidemien.

Die Lähmungen beider Beine waren sehr oft kombiniert mit Bauchmuskellähmungen und Lähmung der Rückenmuskulatur, während diejenigen der Arme oft vergesellschaftet waren mit Nacken- und Halslähmungen. Auch kamen diese oft bei rein zerebralen Formen zur Beobachtung. Bei der Parese eines Arms war oft eine isolierte Lähmung einer Muskelgruppe (Deltoideus), bei solchen der Beine des Quadriceps im Höhestadium bemerkbar. Wie es zum Begriff der atonischen Lähmung gehört, waren die Sehnen-(Patellar-)Reflexe meist herabgesetzt oder erloschen, während die Bauchdeckenreflexe in ihrem Verhalten wechselten. Bezüglich der 
einen Unterabteilung der zerebralen Form, derjenigen mit Bulbärsymptomen, war eine Lähmung (meist einseitig) des Facialis in 13 Fällen nachweisbar. Augenmuskellähmung mit Sehstörung bestand in 4, Schlucklähmung in 2 Fällen; Sprachstörungen wurden 2 mal beobachtet, Stottern und Grimassieren ebenfalls je 1 mal. Meningitische Reizsymptome wurden in 15 Erkrankungen angegeben. Ataktischer Gang, Gleichgewichtsstörungen und primäre trophische Störungen wurden je 1 mal erwähnt. Plötzlicher Tod nach relativem Wohlbefinden und ohne Lähmungserscheinung lieB sich in einem Falle beobachten; ein Rückfall mit Tod noch 10 Wochen nach Einsetzen der ersten Erscheinungen war $1 \mathrm{mal} \mathrm{nachweisbar.} \mathrm{Abortive}$ Formen wurden 8 mal sicher erkannt. Sonst traten noch stark abortivverdächtige Erkrankungen in Bleichenbach, Lampertheim, Bensheim, GroBUmstadt, Guntersblum und Wallertheim (etwa $25 \mathrm{mal}$ ) in die Erscheinung, die aber bei unserer Statistik nicht mitgezählt sind. Die Inkubation betrug nach unseren Beobachtungen 4-5-6-7 Tage.

Gestorben sind, abgesehen ron dem einen Todesfall an Tuberkulose (Horchheim Nr. 8), der nicht mitrechnet, von den 208 Poliomyelitisfällen in den beiden Epidemien innerhalb eines Zeitraums von 2-4-6-1418-24-35-75 Tagen nach Beginn der Erkrankung im ganzen 28; es berechnet sich danach die Mortalitätsziffer auf 13.46 Prozent. Während der Epidemie vom Jahre 1909/10 starben im ganzen von 33 Erkrankungen 6 Personen, während in derjenigen von 1913/14 (die Fälle von 1911/12 sind mitgezähIt) auf 175 Erkrankungen 22 zugrunde gingen. Die Sterblichkeit beträgt demnach im ersten Falle nahezu 18.2 Prozent (in Garbenteich allein 3 Todesfälle bei 8 Erkrankungen), im zweiten etwa 12.5 Prozent. In manchen Orten (Garbenteich, Bisses, Wahlen, Arnsheim) trat die Krankheit sehr bōsartig auf, während wieder in anderen Gemeinden (Osthofen, Heppenheim a. d. W., Nieder-Florstadt, Wallertheim, Arheilgen) der Verlauf ein günstiger war. An Erscheinungen der Landryschen Paralyse (mit Respirationslähmung) starben im ganzen 19; mehr an Bulbär(enzephalitischen) Symptomen endeten 9. Von den 7 Erwachsenen über 10 Jahre starb nur eine Person. Wir konnten also die Wickmannsche Erfahrung, wonach die Mortalität bei Erwachsenen doppelt so grob sein soll wie bei Kindern unter 10 Jahren, nicht bestätigen. Bezüglich der Heilbarkeit der Frkrankung konnten wir eine völlige Genesung mit restitutio ad integrum, wobei die 8 Abortivfälle mitzählen, an 53, Besserung (Parese geblieben) in 78 und Dauerlähmung in 49 Fällen konstatieren, wobei diese Dauerlähmung als bleibende noch nach 3 bis 5 Jahren bei 21 Personen festzustellen war. Die Morbidität betrug in den letzten 5 Jahren zusammen bei einer rund angenommenen Bevölkerungszahl des ganzen GroBherzogtums Hessen von 1300000 Einwohnern 1.6 auf 10000 Ein- 
wohner. Sporadische Erkrankungen in den Jahren 1911/12 wurden 3 mal erwähnt. Bezüglich des pathologisch-anatomischen Befundes ergeben die zwei Sektionen (Worms-Horchheim Nr. 11 und GieBen-Lollar) denselben Befund makroskopisch, wie er schon oft beschrieben ist.

In ätiologischer Hinsicht wurde bei den vielen Poliomyelitiserkrankungen im GroBherzogtum Hessen nur 2 mal eine Erkrankung der Haustiere (Friedberg-Ossenheim und Darmstadt Arheilgèn) erwähnt, obwohl amtlich speziell bei den Erhebungen darauf zu achten hingewiesen wurde. In dem zweiten Falle, wo ein Schwein nach 3 Wochen seit Beginn der Erkrankung des Kindes einging, war kaum ein Zusammenhang zu konstruieren; im ersten Falle handelte es sich um eine Erkrankung von Hühnern, wie sie in landwirtschaftlichen Gegenden oft vorkommt, demnach nichts Besonderes darstellt. Ein Zusammenhang zwischen Kinderlähmung und ähnlichen Erkrankungen der Haustiere scheint demnach nach unseren Erfahrungen nicht zu bestehen. Ebensowenig erkrankten Personen, die einmal die Krankheit durchgemacht hatten, zum zweiten Male daran; das einmalige Überstehen scheint demnach analog den Tierexperimenten immun zu machen gegen die gleiche Krankheit für mehr oder weniger lange Zeit. Eine gewisse Immunität der einmal befallenen Gegenden konnten wir bei unseren Epidemien nicht nachweisen, da gerade in der Provinz Oberhessen einzelne Kreise, die 1909 heimgesucht wurden, im Jahre 1913 wieder infiziert wurden, wenn auch in den einzelnen. Gemeinden gerade keine neuen Reinfektionen nachweisbar waren. Eine Übertragung der Kinderlähmung durch Insekten wurde in unseren Fällen nie beobachtet, desgleichen eine solche durch Nahrungsmittel und andere leblose Gegenstände (Wäschestücke) nicht erwähnt. Ebensowenig konnten wir einen Anhaltspunkt dafür finden, da $B$ das Poliomyelitis-Virus sich in dem Staub und Schmutz der StraBen aufhält und so die Infektion eventuell durch Inhalation weiter vermittelt, da gerade die erste Epidemie in den Spätherbst bzw. Winter fiel, wo gerade die Regenzeit einsetzte, und die zweite in einem ausgeprägt regnerischen Sommer sich abspielte. Bezüglich der von Müller erwähnten Tatsache der Einschleppung der Seuche durch Gewerbtreibende, die viel in infizierten Gegenden herumreisen oder viel Verkehr mit auswärtigen Personen treiben, wie Gastwirte, Händler, Kutscher, Arbeiter mit langer Bahnfahrt, Bahn- und Postbeamte usw., konnten wir die Erfahrung machen, daß der Beruf des Vaters für die Gefährdung seiner Familie nur im allgemeinen einen Anhaltspunkt geben kann, da dieser nach den ländlichen, industriellen Bezirken und nach den Orten, wo viel Bahnpersonal wohnt, sebr wechselt. Immerhin konnten wir auch nach beifolgender Berufsstatistik der Familienvorstände, soweit solche erhältlich war, ein Zurückstehen der seBhaften Bauernbevölkerung 
bemerken, gegenüber dem Handwerker- und Fabrikarbeiterstand. Die überaus starke Beteiligung der Kinder von Wirten, Krämern, Beamten und Schuhmachern blieb immerhin bemerkenswert:

1. Selbständige Handwerker . . . . . . . . . 25

2. Darunter Schuhmacher . . . . . . . . . 6

3. Fabrikarbeiter, Tagelōhner . . . . . . . . . . . 64

4. Unselbständige Handwerker (nicht in Fabriken). . 19

5. Landwirte und Knechte. . . . . . . . . . 29

6. Wirte, Metzger, Krämer, Händler, Kaufleute . . 19

7. Bahn- und Postbeamte . . . . . . . . . . 14

8. Andere Beamte des Staats oder der Gemeinde . . 22

9. Kutscher, Chauffeure, Ingenieure, Musiker usw. . . 6

10. Krankenhauspersonal . . . . . . . . . . . 2

Diese Statistik lehrt aber auch, daB die Kinderlähmung nicht an besonders ärmliche und unsaubere Verhăltnisse gebunden, und daB keinesfalls die ärmste Bevölkerung vorzugsweise befallen war. Es erkrankten ebensogut Kinder von Pfarrern, Lehrern, Gewerbetreibenden, Beamten, Landwirten, wie Kinder von Fabrikarbeitern, Tagelöhnern und Knechten.

Als Eingangspforte für das Gift und wohl auch als Ausscheidungsort desselben ist nach den experimentellen Untersuchungen und nach dem Verlauf der seitherigen Epidemien, wie auch speziell nach den Ergebnissen der Epidemien in Hessen die Schleimhaut der Luftwege und des Magendarmkanals anzusehen. Ebenso muB man entsprechend den Tierversuchen annehmen, daB das Gift, vielleicht durch Tröpfcheninhalation, wie bei der Tuberkulose, vielleicht auch durch direkten Kontakt (Liebkosungen, Wäschestücke usw.) in die Schleimhaut des Mundes und des Nasenrachenraums kommt, dort zum Teil den Lymphbahnen der Geruchsnerven entlang zum Zentralnervensystem gelangt und dann entweder bei Kindern, die empfänglich sind, die Erkrankung direkt verursacht oder zum Teil verschluokt wird, in den Magen gelangt und dann wieder durch die LymphgefäBe dem Gehirn und Rückenmark zugeführt wird. Ein Teil der Krankheitskeime kann dann analog den Tierexperimenten wieder den Geruchsnerven entlang zur Nasenschleimhaut zurückwandern und von dort aus wieder durch die Absonderungen ausgeworfen werden und so eine neue Infeltion verursachen. Bei ãlteren Personen, die keine so empfindliche Schleimhaut mehr haben, mithin nicht so empfänglich sind, bleiben die Keime in der Nasenrachenschleimhaut sitzen, ohne daB sie irgendwelche Erkrankung hervorrufen. Diese bilden dann, wie wir dies auch bei anderen Infektionskrankheiten sehen können, die gefürchteten Bazillen-(Keim-)Träger. 
In epidemiologischer Beziehung konnten wir danach in den letzten 5 Jahren im Großherzogtum Hessen $\mathrm{z}$ wei groBe Epidemien von Kinderlähmung feststellen; eine im Jahre 1909/10 mit Durchseuchung der Provinz Oberhessen, ausgehend von der Epidemie in Hessen-Nassau auf den nördlichst gelegenen Teil der Provinz, auf den Kreis Alsfeld, und dauernd von Mitte Juni bis Ende November mit im ganzen 7 Erkrankungen und dann übergehend auf den Kreis Gießen im September 1900 bis zu Beginn des Jahres 1910 mit 17 Krankheitsfällen. Zu gleicher Zeit sprang die Krankheit über auf die benachbarten Kreise Friedberg mit 3 und auf Büdingen mit 1 Erkrankung, wăhrend die anderèn Kreise und speziell die Provinzen Starkenburg und Rheinhessen frei blieben. Die Epidemie in Garbenteich mit 8 Erkrankungen herrschte von Mitte Oktober bis Ende November und war übertragen aus Niederwetter bei Marburg. Die kleineren Epidemien in Wieseck und Daubringen mit je 3 Krankheitsfällen spielten sich im Winter (November, Dezember und Januar) ab. Diese Epidemie nahm also ibren Weg ron Norden nach Süden. Dann kamen mehr sporadische Erkrankungen im Laufe der nächsten Jahre vor, so im Kreise Alsfeld in Arnshain (1910 und 1912), Nieder-Gemünden .(1911), im Kreise Gießen in Klein-Linden (1910) und in Steinberg-Watzenborn (1911), im Kreise Lauterbach in Hörgenau (1910) und im Kreise Büdingen in Stockheim (1910). Berücksichtigt man dabei, $\mathrm{dab}$ in Klein-Linden auch im November 1909 ein Poliomyelitisfall vorkam, in Hörgenau im Juni 1913, sowie im Krejse Heppenheim in Zotzenbach im Jahre 1910 und 1913, so ist die Vermutung, daB dies gehăufte Auftreten in den einzelnen Jahren durch Bazillenträger (Dauerausscheider) bewirkt war, nicht von der Hand zu weisen.

Die andere große Epidemie des Jahres 1913/14 nahm dagegen den entgegengesetzten Lauf, nämlich von Süden nach Norden. Sie ging vom GroBherzogtum Baden mit dem Mittelpunkt Heidelberg aus und griff zunächst auf den Kreis Bensheim der Provinz Starkenburg über und verbreitete sich dort epidemisch in den Industrieorten Lampertheim und Bensheim mit einzelnen Ausstreuungen in Nordheim, GroB-Rohrheim und Lorsch. Zu gleicher Zeit trat ein gehäuftes Auftreten ein in der Industriestadt Offenbach mit ihrer fluktuierenden Arbeiterbevölkerung und von Thüringen eingeschleppt in den Industrieort Egelsbach mit einem einzigen Auslâufer in dem Offenbach sehr nahen Obertshausen. Dann kam die Seuche nach dem Kreise Darmstadt mit epidemischem Auftreten in der Stadt Darmstadt und in Arheiligen mit einzelnen Ausstreuungen in Wixhausen und Eberstadt. Im Kreise Grob-Geran wurden befallen im Zeitraum von August bis Dezember sechs Gemeinden, die alle räumlich ziem- 
lich weit voneinander liegen. Im Kreise Heppenheim stammten die Erkrankungen in Neckar-Steinach und Wimpfen aus dem nahen Baden, während für Viernheim mit seiner starken Arbeiterbevölkerung derselbe Infektionsmodus vorgelegen haben dürfte. Die groBe Epidemie in GroBUmstadt (Kreis Dieburg) hatte wahrscheinlich ihren Ausgangspunkt in dem nahen Darmstadt und griff über nach Hergershausen, GroB-Bieberau und den Nachbarorten Heubach und Raibach. Die Utbertragung vom GroBherzogtum Baden (Friedrichsdorf) wurde angegeben für Kailbach im Kreise Erbach mit Ausstreuern in zwei einzelne kleine Orte.

$\mathrm{Zu}$ gleicher Zeit zeigte sich die Poliomyelitis epidemisch auftretend in der Kreisstadt Worms der Provinz Rheinhessen seit Mai 1913 und hieran anschließend mit der großen Epidemie in dem $1 / 2$ Stunde entfernten Horchheim, dem gehäuften Auftreten in den nahe beieinander liegenden Orten Osthofen, Heppenheim a. d. W., Abenheim, Bechtheim, Hamm mit einzelnen Erkrankungen in Rheindürkheim, Gundheim, Herrnsheim, Weinsheim und Gimbsheim. Im Krreise Bingen trat die Infektion zuerst im Juni in Gaulsheim auf, übertragen wieder durch Erkranknngen aus Lahr in Baden, und in der nahen Kreisstadt Bingen, sowie in Büdesheim. Auch der benachbarte Kreis Alzey wies 4 Krankheitsfalle von Poliomyelitis auf, wovon allein 2 auf die Kreisstadt Alzey kamen, bei denen die erste Infektion während einer Reise von Köln herrühren sollte. Auch die Kreisstadt Mainz zeigte ein gehäuftes Auftreten (6 Erkrankungen) von Ende Juni bis Mitte November des Jahres 1913. Der Kreis Oppenheim wies in drei Gemeinden 5 Fälle auf, davon allein für Wallertheim 3. Der eine Fall in Guntersblum war von Osthofen eingeschleppt.

Aber auch die Provinz Oberhessen warde in der Epidemie im Jahre 1913/14 nicht verschont. Im Kreise Alsfeld und Lauterbach traten einzelne Erkrankungen auf, während es zu einem mehr epidemischen Verlauf unter Einzelerkrankungen in weit voneinander liegenden kleinen Orten im Kreise Büdingen in den Orten Bisses und Wippenbach, im verkehrsreichen Kreise Friedberg, im nahen Nieder-Florstadt mit Ausstreuungen in Ossenheim und Staden während der Monate August bis Dezember und zuletzt im hreise Schotten in den nahe gelegenen Gemeinden Glashütten und Ober-Lais (4 Fälle) mit vorherigen Ausläufern in Burkhards, Ober-Seemen, Schotten und Eschenrod während der Monate September, Oktober, November und Dezember 1913, sowie Januar bis März 1914 kam. Also auch hier zeigte sich wiederum im kleinen der Zug von Süden nach Norden. Die Einzelerkrankung in Lang-Göns ( reis GieBen) im Januar 1914 ist als Nachläufer der Epidemie zu betrachten. 
Grobherzogtum

HES SEN

NASSAU

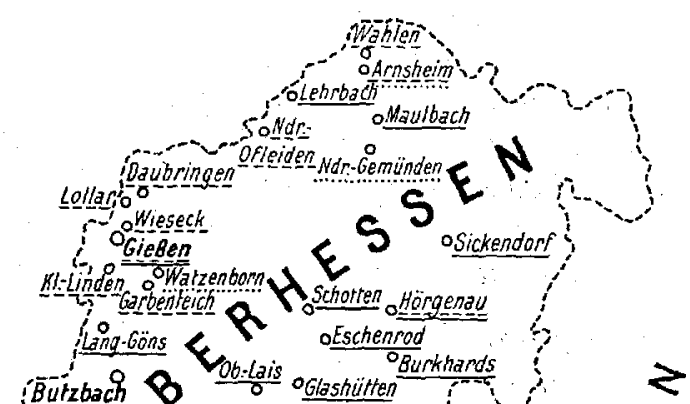

¿Burzbach 8 Wisseso Wigpenbch oober-Seement

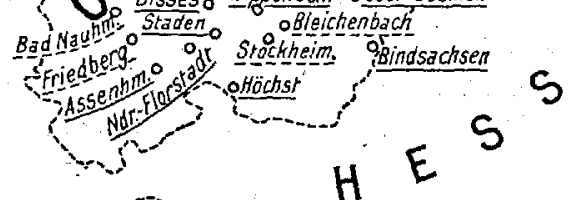

?

Öffenbach

H

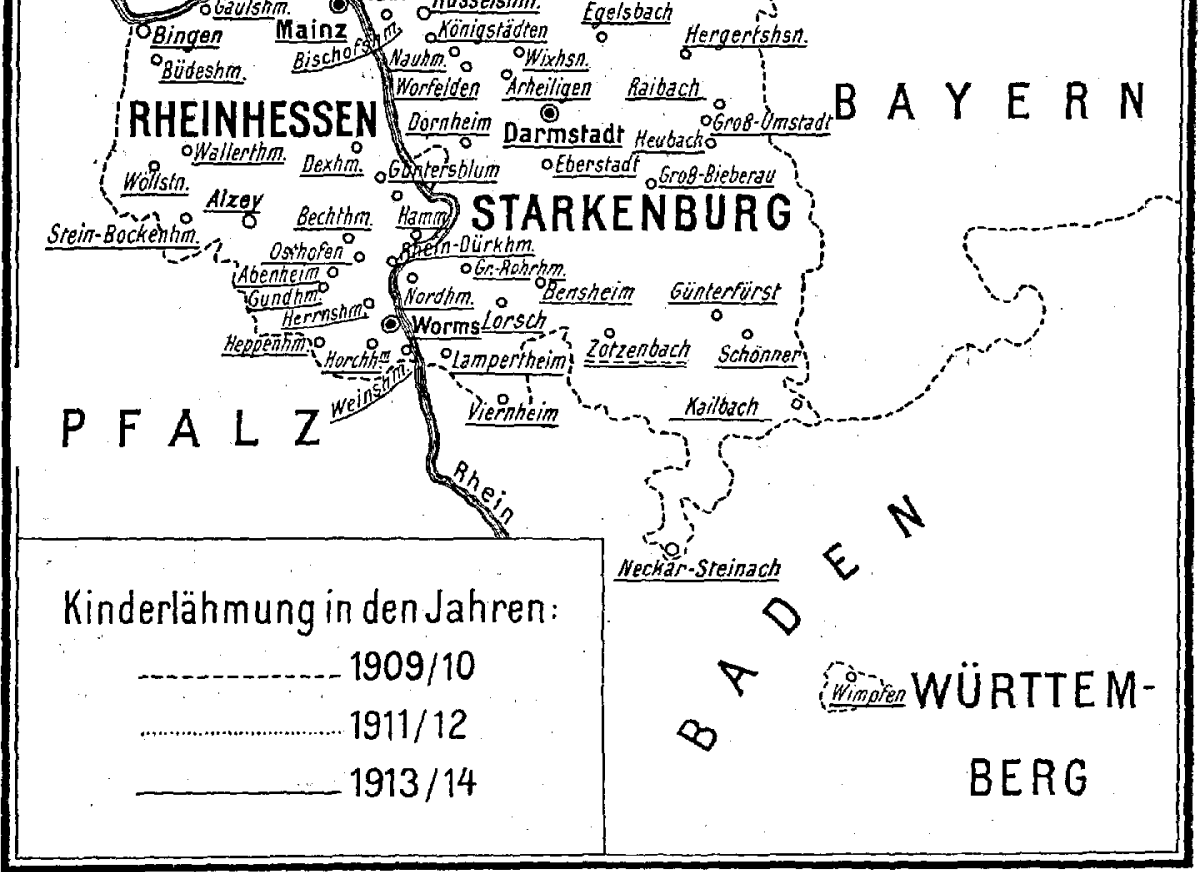

Fig. 2. 
Auch bei unseren Epidemien konnten wir in nahezu $1 / 3$ der Erkrankungsfälle (63 mal) die Ubertragung des Leidens von Person zu Pers on nachweisen, aber weniger durch die erkrankten Kinder selbst

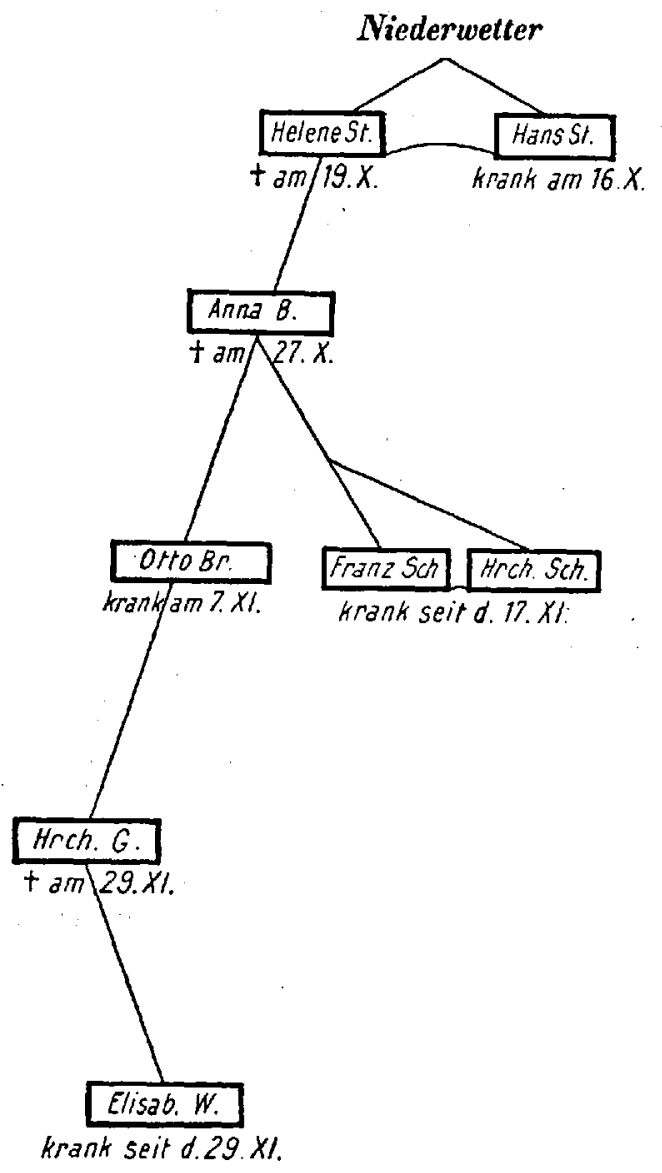

Fig. 3.

Beispiel für eine Kontaktepidemie (Garbenteich, s. S. 78).

(nur $25 \mathrm{mal}$ ), als durch scheinbar gesunde Geschwister und durch erwachsene Zwischenglieder (Bazillenträger $38 \mathrm{mal}$ ), wie ich dies schon im Jahre 1909 gelegentlich der Epidemie in Garbenteich (Kreis GieBen) demonstrieren konnte. ${ }^{1}$

- Vortrag gehalten in der medizinischen Gesellschaft zu Gießen, veröffentlicht im Korrespondenzblatt der ärztl. Vereine d. Großherzogtum Hessen. 1909. Nr. 12. 
Der Nachweis des Zusammenhanges der einzelnen Fälle untereinander ist gewöhnlich in großen Industrieorten und in großen Städten mit stark fluktuierender Bevölkerung sehr erschwert, wenn nicht unmöglich. Jedoch gelingt auch hier der Kontaktnachweis unter Hilfe von Abortivfällen sehr oft, wenn man nur rūhrig danach fahndet und frühe genug Erhebungen an Ort und Stelle anstellen kann. Sind erst einmal einige Monate seit den ersten Erkrankungen darüber hinweggegangen, so ist natürlich das Bild verwischt, und die Ätiologie schwer zu eruieren. Deutliche Beispiele von kleinen Gruppenerkrankungen bieten die Poliomyelitisfälle in Daubringen (Kreis GieBen), Bisses (Kreis Büdingen), Bensheim, Hergershausen (Kreis Dieburg) und in Offenbach:

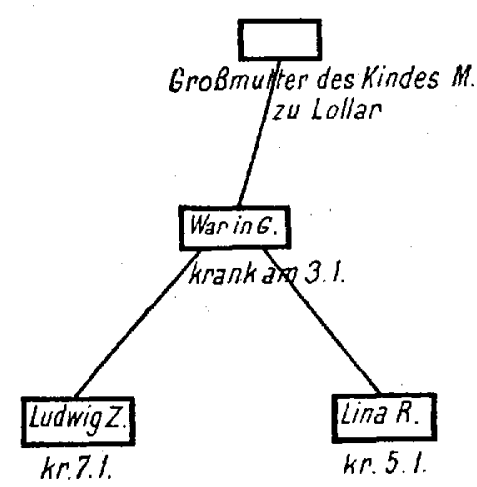

Fig. 4.

Gruppenerkrankung Daubringen.

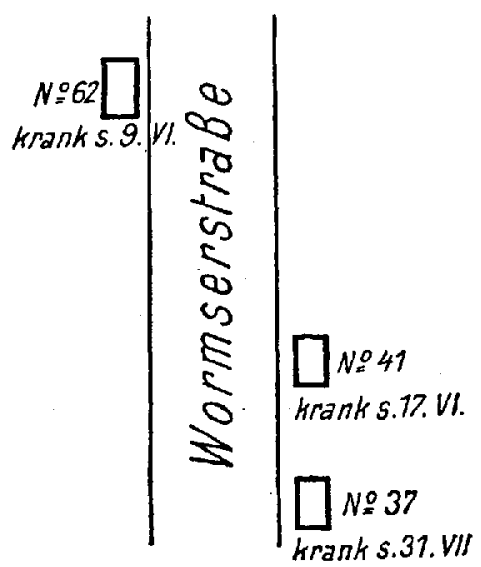

Fig. 6.

Gruppenerkrankung Bensheim.

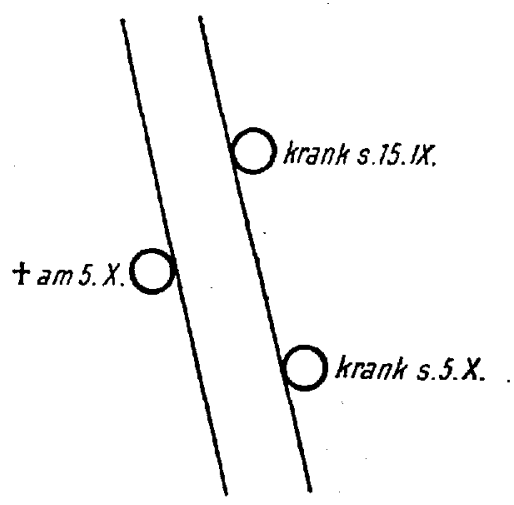

Fig. 5.

Gruppenerkrankung Bisses.

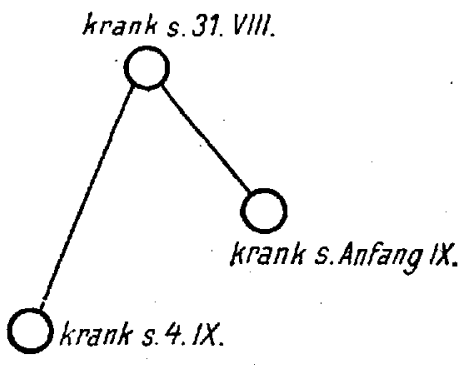

Fig. 7.

Gruppenerkrankung Hergershausen. 
Eine deutliche Herdbildung in 3 Fällen in einer StraBe und 1 Fall in einer NebenstraBe konnten wir in Offenbach festgestellt sehen (Bericht von Dr. Klein):

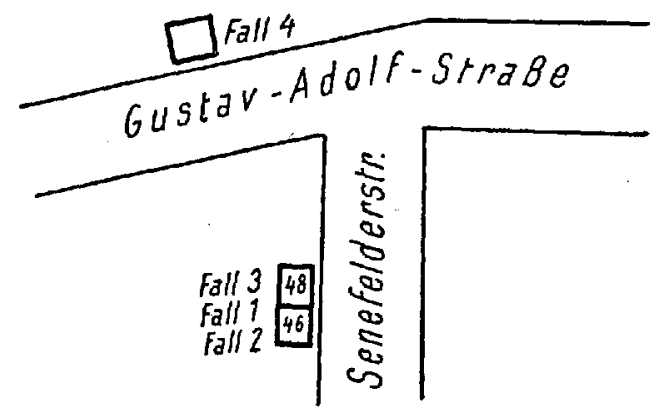

Fig. 8.

Grappenerkrankung in Offenbach.

Ein Beispiel für eine Spitalinfektion bieten die Fälle aus Darmstadt bzw. Arheilgen:

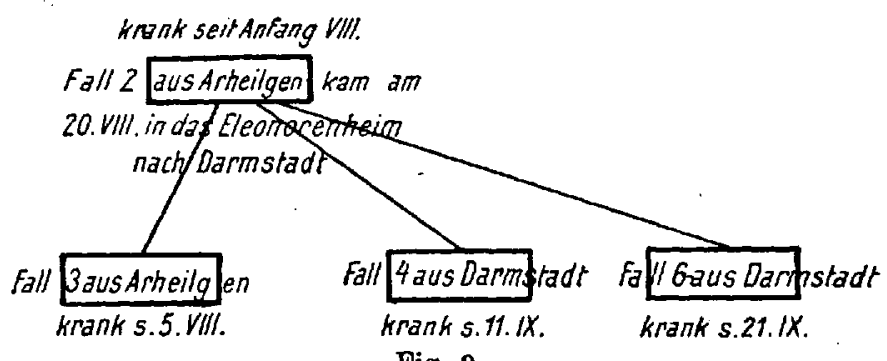

Fig. 9.

Ein Bild einer richtigen Insel- und Bezirkerkrankung, wo eine ganze Gegend infiziert war, bietet die Epidemie in Horchheim (Kreis Worms). Bericht des dortigen Arztes (s. S. 106).

Der Plan ron GroB-Umstadt (Kreis Dieburg) bietet ein anschauliches Bild, wie ein Fall an den anderen anknüpft, und wie trotz räumlicher Entfernung die Ätiologie der einzelnen Erkrankungen festzustellen war. Die Ermittelungen verdanke ich der Güte der Herren Kollegen Gefe und Reuscher (s. S. 89).

Auch wir konnten gelegentlich der Epidemien in Hessen die Erfahrung machen, daB die Verschleppung der einzelnen epidemischen Herde unabhängig von der Dichte der-Bevölkerung ist. In den großen Städten Nainz (6 Erkrankungen), Darmstadt (9), Offenbach (7) und Worms (5) 


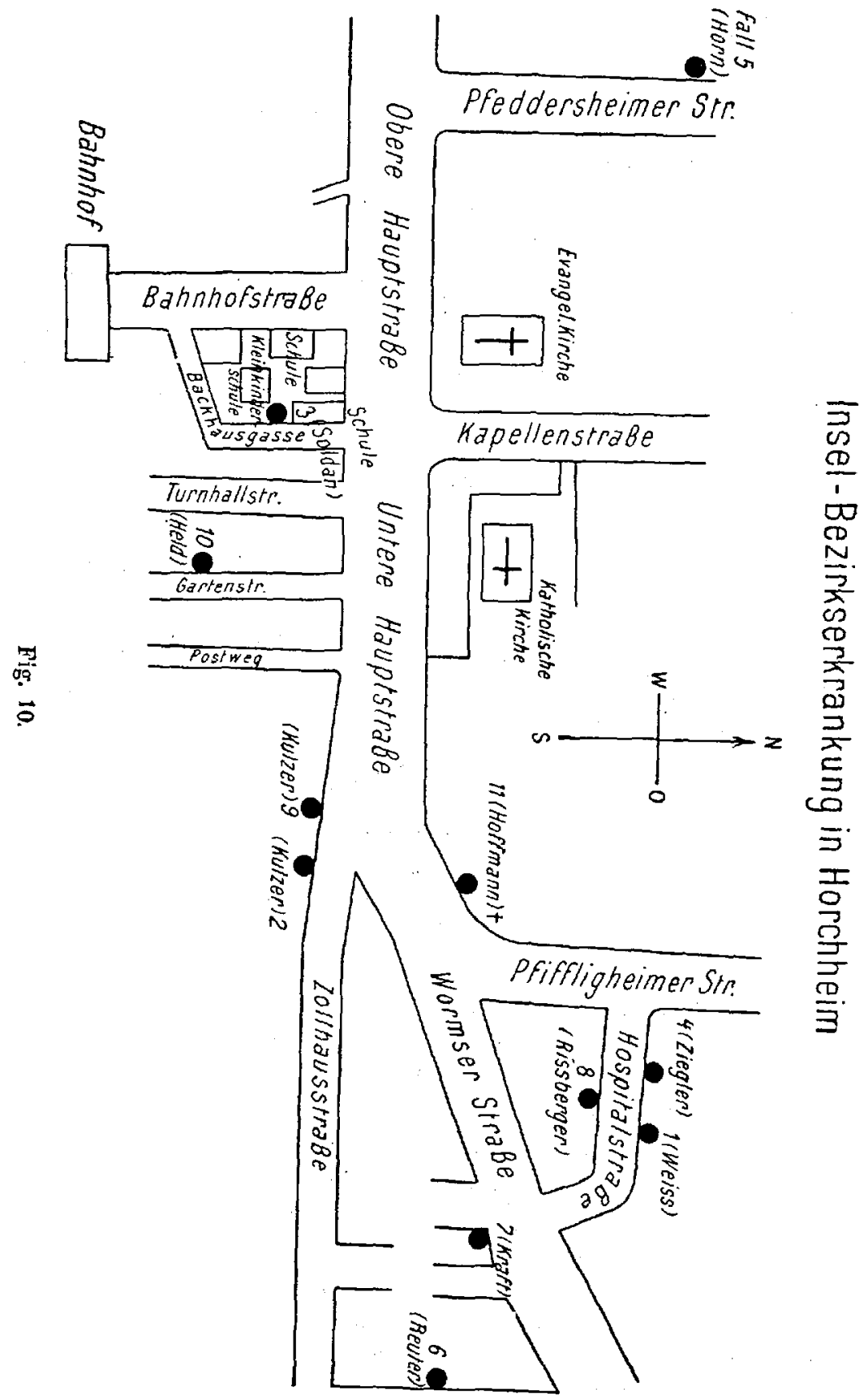


kamen nur verbältnismäßig wenige Krankheitsfälle vor - in Gießen mit seinen 31500 Einwohnern sogar nur ein Fall -, wăhrend die mittleren Städte und Orte (GroB-Umstadt mit 17, Lampertheim mit 15, Horchheim mit 11, Bensheim mit 5, Egelsbach mit 6 und Arheilgen und Viernheim mit je 3 verhältnismäßig stark heimgesucht wurden. Am meisten befallen waren wiederum im Verhältnis zu ihrer Bevölkerungsdichte ganz kleine Gemeinden ron 200 bis 500 bis 900 Einwohnern (Bisses, Wahlen, Nieder-Ofleiden, Ober-Lais, Hergershausen und Garbenteich) mit meist ländlicher Bevölkerung. Woher dies kommt, entzieht sich bis jetzt unserer sicheren Beurteilung. Der Mangel an Disposition kann hier nicht allein maßgebend sein. Auch die Annahme, daB ein Teil der städtischen Bevölkerung durch nicht beobachtete Abortivfälle immun geworden sei, ist nicht stichhaltig. Ein örtlicher Zusammenhang zwischen Erkrankung und Infektion (benachbarte Lage) lieB sich bei uns konstruieren in 15 Fällen; zeitlich fielen die Erkrankungen zusammen in 36 Krankheitsfällen. Dauerausscheider, deren Möglichkeit analog den Erfahrungen bei Typhus, Paratyphus und besonders bei Diphtherie und Genickstarre, wo ja die Eingangspforte ebenfalls im Nasenrachenraum liegt, zugegeben werden muB, muBten wir annehmen $4 \mathrm{mal}$ (s. S. 100). Geschwister- und Familienerkrankungen, die aber nicht auf einer gemeinsamen, gleichzeitigen Infektion berunten, wurden im ganzen 6 mal beobachtet, so daB die Anzahl der Fälle, wo sich kein Zusammenhang konstruieren lieB, auf 84 (von 208) zusammenschrumpft, eine Zahl, die sich noch erniedrigen läßt, wenn man die einzelnen sporadischen Erkrankungen und die drei aus PreuBen stammenden der Gießener Kinderklinik abzählt. Der Grund, warum so wenig Geschwistererkrankungen vorkamen, wo doch in den meisten Familien mehrere Kinder vorhanden waren, mag darin liegen, daB nicht alle Kinder zur Poliomyelitiserkrankung gleich disponiert erscheinen, und daB es besonders bei solchen zum Ausbruch der Krankheit kommt, bei denen eine Läsion der Nasenrachenschleimhaut (Schnupfen, Katarrh, Halsentzündung) oder eine Alteration des Magendarmkanals angenommen werden muB. Ein gut Teil der anderen trägt, ähnlich wie in der Epidemiezeit bei Genickstarre und Diphtherie, in den Krypten der Mandeln und den adenoiden Wucherungen an den Nasenmuscheln und in den Nebenhöhlen Bazillen bei sich und wird so, ohne krank zu sein, zu Bazillentrăgern. Der Erreger findet sich, analog wie bei anderen Infektionskrankheiten, nur bei den kranken Menschen, den Rekonvaleszenten und in der nächsten Umgebung der Erkrankten, somit bei Personen, die direkt oder indirekt mit den Kranken in Berührung gekommen sind. Eine Ubiquität des Erregers der Kinderlähmung kann demnach unseres Erachtens nicht angenommen werden. 
Tabelle I.

\begin{tabular}{|c|c|}
\hline Nr. & $K r e i s$ \\
\hline 1 & Alsfeld . . . \\
\hline 2 & $"$. \\
\hline 3 & $"$. \\
\hline 4 & $"$. \\
\hline 5 & GieBen . . \\
\hline 6 & Friedberg . \\
\hline 7 & GieBen. . \\
\hline 8 & Friedberg . \\
\hline 9 & GieBen . . \\
\hline 10 & " . \\
\hline 11 & ", \\
\hline 12 & \\
\hline 13 & Alsfeld . . \\
\hline 14 & Friedberg . . \\
\hline 15 & GieBen . . . \\
\hline 16 & Büdingen . . \\
\hline
\end{tabular}

\section{GieBen . Lauterbach GieBen . Büdingen \\ Alsfeld \\ Heppenheim}

Gemeinde

Zeit

Zahl

\begin{tabular}{|l|l|l} 
Wahlen. . . . . . & Juni & 1
\end{tabular}

,...$\cdot$.

$$
\text { , }
$$

GieBen

Friedberg .

Garbenteich

Bad-Nauheim

Klein-Linden

Lollar

Wieseck

Garbenteich

Nieder-Ofleiden

Batzbach

Wieseck

Bleichenbach

1910.

Daubringen . . . . Januar

Hörgenan . . . . . März

Klein-Ijinden .

Stockheim.

Arnshain

Zotzenbach

1911.

\begin{tabular}{l||l}
1 & Alsfeld \\
2 & Gieben
\end{tabular}

Nieder•Gemünden .

Steinberg

\section{2.}

1 Alsfeld .

Arnshain

1913.

Lampertheim . . . $\quad$ April

" . . . Mai

Bensheim . . . .

Offenbach . . . .

Offenbach . . . . .

Worms . . . . .

Rheindürkheim

Lampertheim

Bensheim

Hamm

September 1

\begin{tabular}{l|l} 
September & 1
\end{tabular}

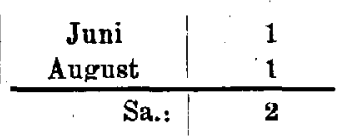

\begin{tabular}{|c|c|} 
Mai & 4 \\
April & 1 \\
Mai & 1 \\
$" \prime$ & 3 \\
Juni & 1 \\
J" & 1 \\
Juli & 3 \\
\hline Sa.: & 19
\end{tabular}


Tabelle I. (Fortsetzung.)

\begin{tabular}{|c|c|c|c|c|c|c|c|c|c|c|c|}
\hline \multirow[t]{3}{*}{ Nr. } & \multicolumn{4}{|c|}{$\mathrm{K}$ r e is } & & \multicolumn{4}{|c|}{ Gemeinde } & Zeit & Zahl \\
\hline & \multicolumn{11}{|c|}{1933.} \\
\hline & & & & & & & & & & Transport: & 19 \\
\hline 11 . & Bingen . & & . & . & . & Gaulsheim . & . . & . & . & Juni & 1 \\
\hline 12. & Darmstadt & & . & . & . & Arheilgen . . &. & . & . & $"$ & 1 \\
\hline 13 & Mainz . . & & . & . & . & Mainz . . & . . & . & . & $"$ & 3 \\
\hline $13 \mathbf{a}$ & Ianterbach & . & . & . & . & Börgenau . & . . & . & . & $\eta$ & 1 \\
\hline 14 & Bensheim . & & . & . & . & Lampertheim & . & . & . & Juli & 7 \\
\hline 15 & " . & & . & . & . & Bensheirn . & . . & . & . & $"$ & 1 \\
\hline 16 & Worms. & . & . & . & . & Worms. . & . . & . & . & " & $\mathbf{3}$ \\
\hline 17 &,$\quad$. & & . & . & . & Horchheim . & . . & - & . & $\eta$ & 10 \\
\hline 18 . & $" \quad$. & . & . & . & . & Hamm . . & . . & . & . & $n$ & 1 \\
\hline 19 & , . . & & . & . & . & Osthofen & . . & . & . & $"$ & 3 \\
\hline 20 & , . . & & . & . & . & Bechtheim & . . & . & . & $"$ & 2 \\
\hline 21 & ". . . & . & . & . & . & Abenhein. . & . . & . & . & $n$ & 1 \\
\hline 22 & Mainz . & & . & . & . & Mainz . . & . . & . & . & , & 2 \\
\hline 24 & Offenbach. & & . & . & . & Offenbach. . & . . & . & - & $"$ & 1 \\
\hline 25 & " , & . & . & . & . & Obertshausen. & . . & . & . & 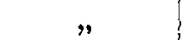 & 1 \\
\hline 26 & Darmstadt & . & $\because$ & . & . & Darmstadt . & . . & . & . & $"$ & 2 \\
\hline 27 & Heppenhoim & . & . & . & . & Viernheim. & . . & . & . & $"$ & 1 \\
\hline 28 & Alzey . . & & . & . & . & Alzey. . . & . . & . & . & Auguat & 2 \\
\hline 29 . & Worms. & & . & . & . & Worms. & . & . & & , & 1 \\
\hline 30 & " . . & & . & . & . & Horchheim & . . & . & • & $n$ & 1 \\
\hline 31 & . & & . & • & . & Abenheim. & . . & . & . & 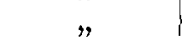 & 1 \\
\hline 32 & , & & . & . & . & Heppenheim a & a. d. & W. & - & $"$ & 3 \\
\hline 33 & . . & . & . & . & . & Gundheim. . & . . & . & . & $"$ & 1 \\
\hline 34 & . . & . & . & . & . & Herrasheim . & . : & . & . & $"$ & 1 \\
\hline 35 & $" \quad$. & . & . & . & . & Weinsheim . & . & . & . & $n$ & 1 \\
\hline 36 & GroB-Gerau & . & . & . & . & Nauheim . & . . & . & - & $\because$ & 1 \\
\hline 37 & $"$ & . & . & . & . & Königstädten. & . . & . & . & 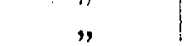 & 1 \\
\hline 38 & $"$ & . & . & . & . & Worfelden. & . . & . & . & $"$ & 1 \\
\hline 39 & Darmstadt. & . & . & . & . & Arheilgen . . & . . & . & • & $n$ & 2 \\
\hline 40 & & . & . & . & . & Darmstadt . & . . & . & v & $n$ & 1 \\
\hline 41 & Heppenheim & . & . & - & . & Viernheim . & . . & . & • & $\because$ & 2 \\
\hline 42 & " & . & . & . & . & Neckar-Steinac & ch & . & & 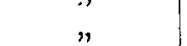 & 2 \\
\hline 43 & Mainz . & . & . & & . & Mainz . . & . . & . & • & $n$ & 2 \\
\hline 44 & Friedberg. & . & . & . & : & Ossenheim & . & . & & ", & 1 \\
\hline 45 & Offenbach . & . & . & . & . & Egelsbach. . & . & : & . & $n$ & 1 \\
\hline 46 & Alsfeld . . & . & . & . & . & Lehrbach ... & . & : & . & :" & 1 \\
\hline 47 & Oppenheim & . & . & . & . & Dexheim . & . & . & & " & 1 \\
\hline 48 & Dieburg . & . & . & . & . & GroB.Umstadt & & . & & $"$ & 6 \\
\hline 49 & " & . & . & & . & Hergershnusen & $n$. & . & &, & 1 \\
\hline 50 & Erbach. & . & . & . & . & Kailbach. . & . & . & & $"$ & 1 \\
\hline 51 & & . & . & . & . & Günterfürst . & . & $\because$ & & $"$ & $\begin{array}{l}1 \\
1\end{array}$ \\
\hline 52 & Offenbach. & . & . & & . & Engelsbach & . & & & September & 5 \\
\hline & & & & & & & & & & Sa.: & 99 \\
\hline
\end{tabular}


Tabelle I. (Fortsetzung.)

\begin{tabular}{|c|c|c|c|c|c|c|c|c|c|}
\hline Nr. & $\mathbf{K}$ I $\mathbf{\theta}$ & $\mathrm{i}$ & & & & Gemeinde & & Zeit & Zahl \\
\hline \multicolumn{10}{|c|}{1913.} \\
\hline & & & & & & & & Transport: & 99 \\
\hline $\begin{array}{l}58 \\
54\end{array}$ & $\begin{array}{c}\text { Worms. } \\
" .\end{array}$ & · & . & . & • & $\begin{array}{l}\text { Heppenheim a. d. } \\
\text { Gimbsheim . }\end{array}$ & & Deptender & $\begin{array}{l}1 \\
1\end{array}$ \\
\hline 55 & Darmstadt & - & . & . & . & Darmstadt . . & . . & $"$ & 6 \\
\hline 56 & $" \quad$. & . & . & . & . & Wixhausen . & . . & " & 1 \\
\hline 57 & Dieburg & . & . & . & . & GroB.Umstadt . . & . & $"$ & 9 \\
\hline 58 & $\eta$ & - & . & . & . & Hergershausen . & . $\cdot$ & $"$ & 2 \\
\hline 59 & $" \quad$. & . & . & . & - & GroB-Bieberau . & . & ", & 2 \\
\hline 60 & Bensheim . & . & . & - & . & Nordheim . . & . & $n$ & 1 \\
\hline 61 & Offenbach & . & . & . & . & Offenbach. . & . . & $n$ & $\mathbf{1}$ \\
\hline 62 & Heppenheim & . & . & . & - & Wimpfen . . & . . & $"$ & $\mathbf{1}$ \\
\hline 63 & Oppenbeim & . & - & . & - & Guntersblum. . & . . & $"$ & 1 \\
\hline 64 & & . & - & $\therefore$ & & Wallertheim . . & - & $"$ & 2 \\
\hline 65 & Bingen . & - & - & . & - & Bingen. . . & . & $"$ & 1 \\
\hline 66 & $n$ & - & - & - & - & Büdesheim . . & . . & $\eta$ & 1 \\
\hline 67 & GieBen . & - & . & . & . & GieBen, Kinderklin & iik . & $"$ & $\mathbf{3}$ \\
\hline 68 & Alsfeld . & . & : & . & . & Maulbach . . & . . & $\eta$ & 1 \\
\hline 69 & Schotten & . & . & . & . & Burkhards. . & . & 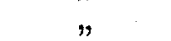 & 1 \\
\hline 70 & " $\quad$. & $\cdot$ & , & . & - & Ober-Seemen . & . & $n$ & 1 \\
\hline 71 & Büdingen . & . & . & . & - & Bísses . . . . & . & , & $\mathbf{2}$ \\
\hline 72 & $n \quad$ & . & - & . & . & Wippenbach . . & - & $"$ & 1 \\
\hline 73 & Bensheim . & - & . & - & . & GroB-Rohrheim . & . . & Oktober & 1 \\
\hline 74 & " & . & . & - & . & Lorsch . . . & . . & $n$ & 1 \\
\hline 75 & Dieburg & • & $\cdot$ & - & • & Groß-Umstadt . & - & $"$ & 2 \\
\hline 76 & - & . & - & . & . & Heubach . . & . & $"$ & 1 \\
\hline 77 & $n \quad$. & . & . & - & - & Raibach . . & . & $"$ & 1 \\
\hline 78 & Oppenheim & . & - & . & . & Wallertheim . & . & $"$ & 1 \\
\hline 79 & Alzey . . & - & . & . & . & Wöllstein . . & . & $"$ & 1 \\
\hline 80 & Bingen. . & . & . & . & . & Bingen . . . & . & $"$ & 1 \\
\hline 81 & Büdingen . & . & . & - & . & Bisses . . . & . & $"$ & 1 \\
\hline 82 & $n$ & . & - & - & . & Wippenbach . & - & $"$ & 1 \\
\hline 83 & $"$ & . & . & - & . & Höchst . . . & . . & $"$ & 1 \\
\hline 84 & . & . & . & - & - & Bindsachsen . & . & $"$ & 1 \\
\hline 85 & Schotten . & $\therefore$ & . & ${ }^{\circ}$ & . & Schotten . & . & & 1 \\
\hline 86 & Lauterbach & . & . & & . & Sickendorf & . & November & 1 \\
\hline 87 & GroB-Geran & - & . & & . & RüBelsheim : & - & " & 1 \\
\hline 88 & & - & - & 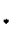 & . & Bischofsheim. . & - & $"$ & 1 \\
\hline 89 & Friedberg . & . & - & & - & Staden . . . & . & $\eta$ & 1 \\
\hline 90 & $n \quad$ & . & . & & - & Nieder.Florstadt & . & $"$ & 2 \\
\hline 91 & Schotten & - & . & & , & Eschenrod. . & - & , & 1 \\
\hline 92 & Mainz . & . & . & & - & Mainz . . . & . & $"$ & 1 \\
\hline 93 & Heppenheim & . & - & & - $\cdot$ & Zotzenbach . . & . & 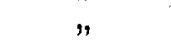 & 1 \\
\hline 94 & Erbach . & . & . & & - & Schönnen. & & $n$ & 1 \\
\hline & & & & & & & & Sa.: & 162 \\
\hline
\end{tabular}


Die Kinderlähmung im Grossherzogtum Hessen uSW. 111

Tabelle I. (Fortsetzung.)

\begin{tabular}{|c|c|c|c|c|c|c|c|c|c|c|c|}
\hline Nr. & $\mathrm{K} \mathbf{r} \mathrm{e}$ & e is & & & & Gem eind & $d e$ & & & Zeit & Zahl \\
\hline \multicolumn{12}{|c|}{1913.} \\
\hline & & & & & & & & & & Transport: & 162 \\
\hline 95 & Alzey - . & . & . & . & . & Steinbockenhein & & . & & November & 1 \\
\hline 96 & Friedberg . & . & . & . & . & Nieder-Florsted & & . & • & Dezember & 1 \\
\hline 97 & GroB-Gerau & . & . & . & . & Dornheim . . & . & . & . & ", & 1 \\
\hline 98 & Offenbach . & . & - & . & . & Offenbach . . & . & . & . & $"$ & 1 \\
\hline 99 & Schotten . & . & . & . & . & Glashütten . & . & . & . & , & 1 \\
\hline \multirow[t]{3}{*}{100} & " & . & . & . & . & Ober-Lais . & . & . & . & $"$ & 1 \\
\hline & & & & & & & & . & & Sa.: & 168 \\
\hline & & & & & & 1914. & & & & & \\
\hline 1 & Schotten & . & . & . & . & Ober-Lais . & . & . & . & Januar & 1 \\
\hline 2 & Gießen . . & - & . & . & . & Lang-Göns & . & . & . & $"$ & 1 \\
\hline 3 & Schotten . & . & . & . & . & Ober-Lais . . & . & . & . & März & 1 \\
\hline \multirow[t]{2}{*}{4} & Darmstadt. & . & . & . & . & Eberstadt . . & . & . & & April & 1 \\
\hline & & & & & & & & & & Sa.: & 4 \\
\hline
\end{tabular}

Die Poliomyelitis kommt zweifelsohne zu jeder Jahreszeit vor; sie bevorzugt aber nach dem Gang der beschriebenen Epidemien den Sommer und Herbst. Auch wir konnten bei den Epidemien im Jahre 1913/14 weitaus die meisten Erkrankungen im Sommer feststellen - Juli 35, August 36, September $44-$, wăhrend in den Monaten Oktober bis Dezember nur 30 Fälle vorkamen. Wenn bei der Epidemie im Jahre 1909/10 der Höhepunkt in den Spätherbst fiel, so mag das darin liegen, daB die Hauptinfektion in Hessen-Nassau erst im Oktober erfolgte.

Die allbekannte Tatsache, daß die Kinderlähmung, wie schon der Name besagt, eine Kinderkrank heit ist und speziell das 1 . bis 5. Lebensjahr am meisten bevorzugt, hat sich auch wieder aus unserer Statistik ergeben. Auf das erste Dezennium kamen von 208 Fällen 197 Erkrankungen, demnach nahezu 95 Prozent, und hierbei wurde das Alter von 5 bis 10 Jahren relativ seltener befallen. Fast $\% / 10$ der Kinder waren nicht älter wie 5 Jahre - zwei Kinder waren erst 5 Monate alt -; nahezu 57 Prozent fielen in die ersten 3 Lebensjahre. Nur ganz vereinzelt fand sich das Leiden bei 7 Personen im Alter von 10 bis 20, bei 2 Personen im Alter von 20 bis 30 und bei 2 Personen im Alter von über 30 Jahren, wie dies folgende Tabelle zeigt: 


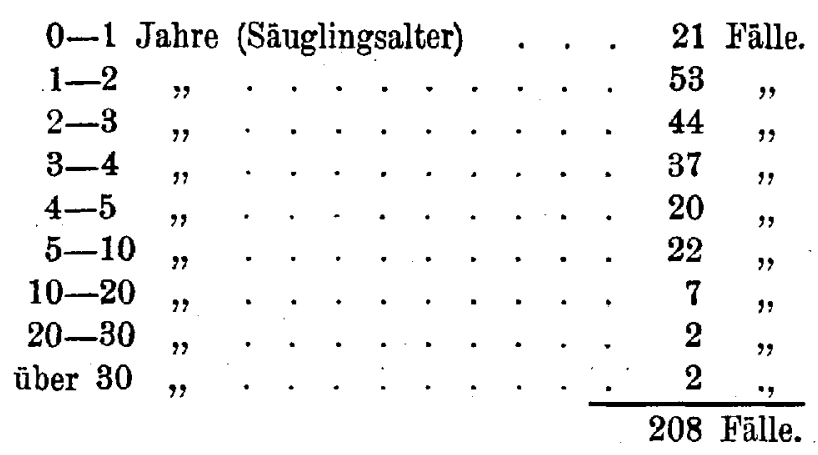

Das mānnliche Geschlecht scheint nach unseren Erhebungen etwas mehr disponiert $z u$ sein, wie das weibliche, wenn auch zugegeben werden muB, daB dies mehr Zufall sein kann. Nach unseren Aufzeichnungen, die für 187 Erkrankungen das Geschlecht angeben, erkrankten 102 Knaben und Männer gegen 85 Mädchen und Frauen.

Wenn nun ein poliomyelitisfreier Ort durch Einschleppung von außen infiziert wurde, so kam es durch den Kontakt der Bepölkerung, wie sich dies auch bei unserer Statistik feststellen lieB, meist zur Gruppenerkrankung und zu kleinen Epidemien. Manchmal blieb aber auch ohne sichtlichen Grund unter denselben äußeren Verhältnissen die Weiterverbreitung aus, und der erste Erkrankungsfall zeigte keine Neigung zur Infektion. Wie kommt es nun, daß in dem einen Teil der Fälle es zur Gruppen- und Herdbildung kam, während dies in dem anderen gleichartigen Teil unterblieb? Die Beantwortung dieser Frage kann nach dem Stande unserer jetzigen Kenntnisse nur eine mutmaßliche sein. MIan kann da zunächst daran denken, da $B$ in einem gewissen Prozentsatz der Poliomyelitis-Erkrankungen die Infektion keine sonderlich schwere war und bald zur Genesung und somit zum Versehwinden der Infektionsquelle führte, so \%. B. bei uns in Lehrbach, Maulbach, Ober-Seemen, GroB-Rohrheim, Gaulsheim, Wöllstein, Steinbockenheim usw. Dann kann man aus dem gleichen Grunde den Umstand ins Feld führen, daB in einem kleinen Prozentsatz der Tod bald eintrat (Lollar, Klein-Linden, Steinberg, Höchst, Eschenrod, Wixhausen). Aus demselben Gesichtspunkte kann man die baldige Internierung und somit auch wirksame Isolierung von der AuBenwelt in einem Krankenhaus bezeichnen (Klein-Linden, GieBen, Butzbach, Bad-Nauheim, Burkhards, Mainz usw.), so daB die betreffenden Personen erst wieder zur Entlassung kamen, als sie nicht mehr infektiös im bakteriologischen Sinne waren. Bei so und so viel Fällen treffen diese Argumente aber nicht zu; ja, das Gegenteil ist eher der Fall. So sehen wir, um nur ein eklatantes Beispiel aus unseren Epidemien herauszugreifen, die sechs 
Poliomyelitis-Erkrankungen im Kreise Groß-Gerau in sechs verschiedenen räumlich ziemlich weit voneinander liegenden Gemeinden und zeitlich nicht zusammenfallend sporadisch auftreten, ohne daB es zur Gruppenerkrankung kommt. Da muß man denn analog den Tierexperimenten, wonach die Utbertragung des Giftes aus den sporadischen Erkrankungen auf Affen nur sehr schwer gelang, und ähnlich wie bei der Cerebrospinalmeningitis annehmen, daB dies Gift schwächer pathogen sei und erst durch Krankenpassagen virulenter wird, wie wir dies auch bei anderen Bakterienarten, die auf kūnstlichen Nährböden lange Zeit weiter gezüchtet wurden und speziell bei der Kuhpockenlymphe hinsichtlich der Virulenzsteigerung bei Tierpassagen schon lange beobachtet sehen. Speziell nach den Untersuchungen im Rockefeller-Institut erwiesen sich auch einzelne Poliomyelitis-Stämme für Affen geringgradig pathogen und konnten erst durch wiederholte Tierpassagen virulenter werden. So konnten wir auch bei unserer Statistik nachweisen, daB ein gut Teil der PoliomyelitisErkrankungen, wo es zur typischen Gruppen- und Epidemiebildung kam, von auswärtigen Epidemien verschleppt sich erwies, somit kontagiöser anzunehmen war, wie wir dies für die Fälle von Wahlen, Nieder-Ofleiden, Garbenteich, Neckar-Steinach, Darmstadt, Egelsbach, Bensheim, Heppenheim a. d.W. und Alzey unterstellten und für andere Orte unterstellen bonnten.

Es bestätigt dies auch die früher schon gemachte Erfahrung, daB, wenn der Infektionsstoff sich weit verbreitet, seine Virulenz zunimmt und eine Virulenzsteigerung des infizierenden Stammes stattfindet. Darauf beruht wohl auch der Umstand, daB bei einzelnen kleinen Epidemien bei uns die Erkrankung eine schwere war, und die Mortalität stieg (Wahlen, Garbenteich, Bisses).

Das sind jedoeh alles nur Mutmaßungen, für die ein sicherer Beweis bis jetzt fehlt. Die Kinderlähmung bietet in mancher epidemiologis chen Hinsicht, speziell bezüglich des Umstandes, daB sie im Verlauf des letzten Jahrzehnts in vielen Staaten auf einmal als Epidemie auftritt und groBe Städte verhältnismäBig verschont, trotz der darüber bis jetzt erschienenen reichhaltigen Literatur noch Rätsel genug, die einer Lösung harren. 